Florida International University FIU Digital Commons

$11-9-2011$

\title{
Perceptions and Preferences of Commercial Fishers in the Florida Keys for Alternative Management Frameworks
}

Brett P. Pierce

Florida International University, bpier006@fiu.edu

DOI: $10.25148 /$ etd.FI11120915

Follow this and additional works at: https://digitalcommons.fiu.edu/etd

\section{Recommended Citation}

Pierce, Brett P., "Perceptions and Preferences of Commercial Fishers in the Florida Keys for Alternative Management Frameworks" (2011). FIU Electronic Theses and Dissertations. 537.

https://digitalcommons.fiu.edu/etd/537 


\section{FLORIDA INTERNATIONAL UNIVERSITY}

Miami, Florida

PERCEPTIONS AND PREFERENCES OF COMMERCIAL FISHERS IN THE FLORIDAY KEYS FOR ALTERNATIVE MANAGEMENT FRAMEWORKS

A thesis submitted in partial fulfillment of the requirements for the degree of MASTER OF SCIENCE

in ENVIRONMENTAL SCIENCE

by

Brett Pierce 
To: Dean Kenneth G. Furton

College of Arts and Sciences

This thesis, written by Brett Pierce, and entitled Perceptions and Preferences of Commercial Fishers in the Florida Keys for Alternative Management Frameworks, having been approved in respect to style and intellectual content, is referred to you for judgment.

We have read this thesis and recommend that it be approved.

$\begin{array}{r}\hline \text { Mahadev Bhat } \\ \hline \text { Ligia Collado-Vides } \\ \hline \text { Pallab Mozumder, Major Professor }\end{array}$

Date of Defense: November 9, 2011

The thesis of Brett Pierce is approved.

\begin{tabular}{r} 
Dean Kenneth G. Furton \\
College of Arts and Sciences \\
\hline Dean Lakshmi N. Reddi \\
University Graduate School
\end{tabular}

Florida International University, 2011 


\section{ACKNOLWEDGMENTS}

First and foremost I would like to thank my advisor, Pallab Mozumder, for his guidance through this process. None of which would have been accomplished without him. Also, I would like to thank my committee members Ligia Collado-Vides and Mahadev Bhat for their guidance on this project as well. Furthermore, I want to thank Bill Kelly of the Florida Keys Commercial Fishermen's Association for his insight into the world commercial fisheries; Everyone who reviewed the survey instrument, and then reviewed it again including Chad Edmondson, Philippe Asselin, members of the EDF, and commercial fishers everywhere; Stephany Alvarez- Ventura; My parents for supporting and believing me. Finally, I want to thank Isabel Quevedo for her support

through this process and the translation of the survey, Mark Ladd, and everyone in Club 158. It is much appreciated. 


\section{ABSTRACT OF THE THESIS \\ PERCEPTIONS AND PREFERENCES OF COMMERCIAL FISHERS IN \\ THE FLORIDA KEYS FOR ALTERNATIVE MANAGEMENT \\ FRAMEWORKS \\ by}

Brett Pierce

Florida International University

Miami, Florida

Professor Pallab Mozumder, Major Professor

The decline of the world's fisheries, and the inability of traditional management frameworks to maintain them, has led managers to adopt new, alternative management frameworks. Alternative management frameworks include marine protected areas (MPA) and dedicated access privileges (DAP). The use of such frameworks has often been shown to be quite unpopular, especially with commercial fishers. In this thesis, commercial fishers' preference for alternative management frameworks is examined in the context of the unique multispecies fisheries of the Florida Keys. By surveying commercial fishers, it was found that the size of operation plays no role in affecting fisher perception of dedicated access privileges. Furthermore, fishers who are organized are less likely to support dedicated access privilege frameworks. Finally, the fishing industry does not support the implementation of dedicated access privileges in the Florida Keys. These findings can provide inputs for managers in developing effective management plans in the region. 


\section{TABLE OF CONTENTS}

CHAPTER

PAGE

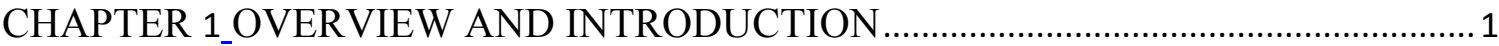

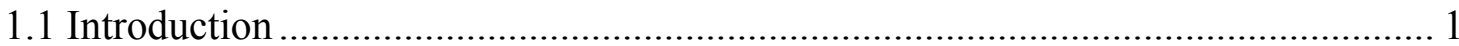

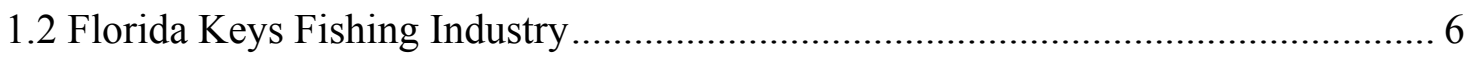

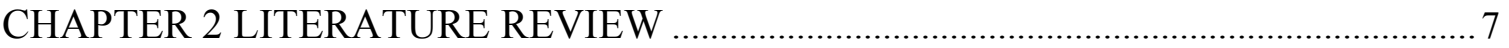

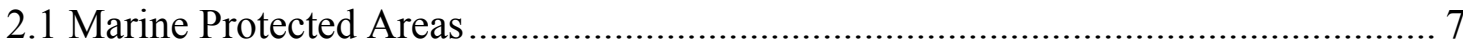

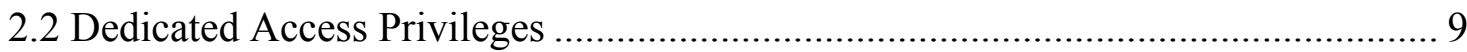

2.3 Drawbacks of Dedicated Access Privilege Frameworks.......................................... 15

2.4 Fisher Perceptions of Marine Protected Areas ........................................................... 17

2.5 Fisher Perceptions of Marine Protected Areas in the FKNMS .............................. 22

2.6 Fisher Perception for Incentive-based Management Frameworks .......................... 23

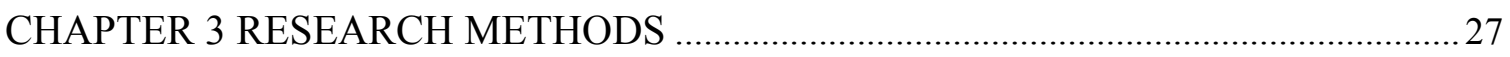

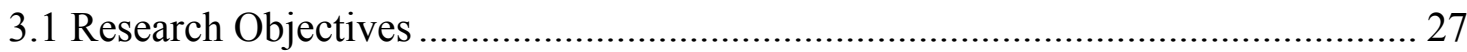

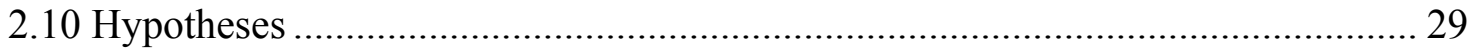

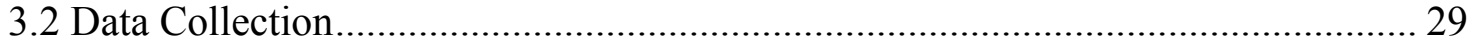

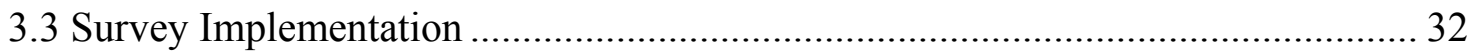

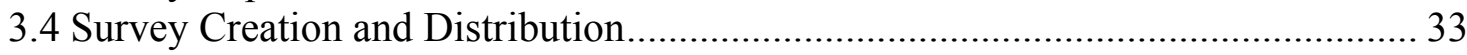

CHAPTER 4 RESULTS AND DATA ANALYSIS …………………………………........

4.1 Description of the Sampled Florida Keys Commercial Fishing Fleet …………...... 35

4.2 Fisher Perceptions of FKNMS as a Fishery Management Tool............................... 42

4.3 Fisher perceptions of alternative management practices......................................... 60

4.3.1 Fisher Perception Regarding and IFQ Framework Benefiting the Industry ..... 61

4.3.2 Fisher Perception Regarding and ITQ Framework Benefiting the Industry .... 63

4.3.3 Fisher Perception regarding IFQs Benefiting Some Operation over Others .... 65

4.3.4 Fisher Perception regarding ITQs Benefiting Some Operation over Others.... 67

4.3.5 Fisher Perceptions Regarding the Cost Effectiveness of a Combination of ITQs

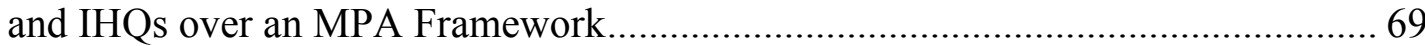

4.3.6 Fisher Perception Regarding Buffer Zones .................................................. 71

CHAPTER 5 DISCUSSION AND CONLUSION …………................................... 72

5.1 Discussion Fisher Perception of Marine Protected Areas as Fishery Management

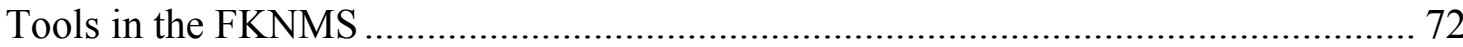

5.2 Fisher Perception for Alternative Management Frameworks ………………….... 76

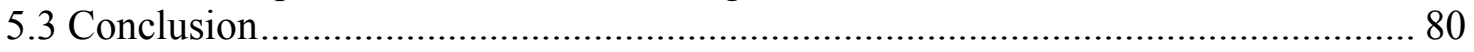

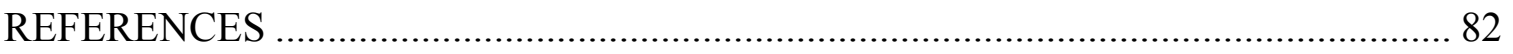

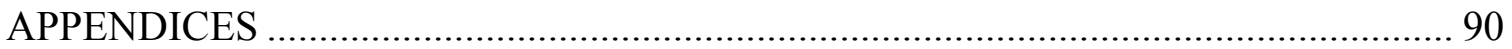




\section{LIST OF TABLES}

TABLE

PAGE

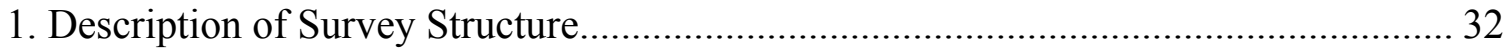

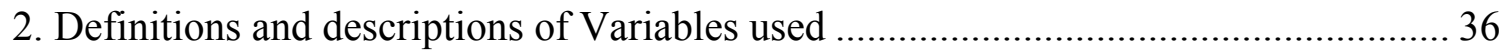

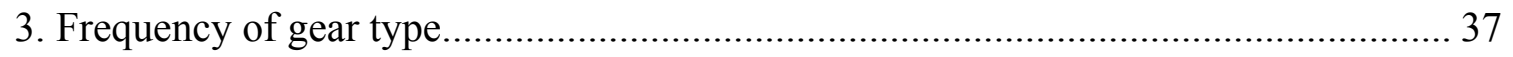

4. Definitions and Descriptive Statistics of Variables used (continued) ......................... 39

5. Fisher Perception on Effects of Florida Keys National Marine Sanctuary on Fishery 43

6. Fisher Perception on Current Status if FKNMS had not been created ....................... 44

7. Fisher Perceptions on Future Fisheries if the FKNMS were Cease to Exist .............. 45

8a. Robust Parsimonious Logit Model of Fisher Belief that an IFQ System would benefit

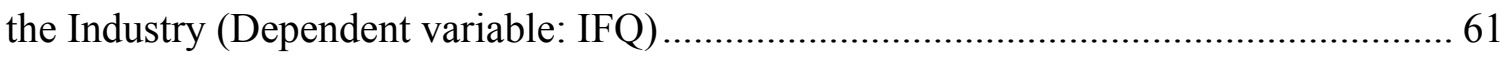

8b. Robust Extended Logit Model of Fisher Belief that an IFQ System would benefit the Industry (Dependent variable: IFQ).....

9a. Robust Parsimonious Logit Model of Fisher Belief that an ITQ System would benefit the Industry (Dependent variable: ITQ). 63

9b. Exteded Logit Model of Fisher Belief that an ITQ System would benefit the Industry (dependent variable: ITQ)

10a. Robust Parsimonious Logit Model of Fisher Belief that an IFQ system will benefit Specific Operations over others (dependent variable: Specific_operation_ifq) .....

10b. Extended Robust Logit Model of Fisher Belief that an IFQ system will benefit Specific Operations over others (dependent variable: Specific_operation_ifq)

11a. Parsimonious Logit Model of Fisher Belief that an ITQ system will benefit Specific

Operations over others (dependent variable: Speciffic_operation_itq).... 68

11b. Extended Logit Model of Fisher Belief that an ITQ System will benefit Specific Operations over others (dependent variable: Speciffic_operation_itq).

12a. Parsimonious Robust Logit Model of Fishers' Perception that a Combination of ITQs and IHQs is more Cost Effective than Marine Protected Areas (dependent variable: itq ihq)...... 
12b. Extended Robust Logit Model of Fishers' Perception that a Combination of ITQs and IHQs is more Cost Effective than Marine Protected Areas (dependent variable:

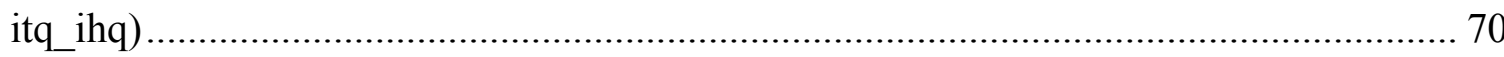

13a. Robust Parsimonious Logit Model of Fishers Support for Buffer Areas around Areas of No-take in the FKNMS (dependent variable: Buffer)........................................ 71

13b. Extended Robust Logit Model of Fishers Support for Buffer Areas around Areas of No-take in the FKNMS (dependent variable: Buffer) ………………............................ 72 


\section{LIST OF FIGURES}

FIGURE

PAGE

1. The Gordon-Schaefer model shows the result of increasing effort on a fishery.

Problems (social, economic, and biological) are realized when the effort increases beyond

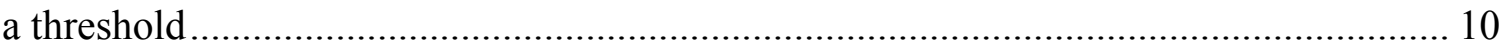

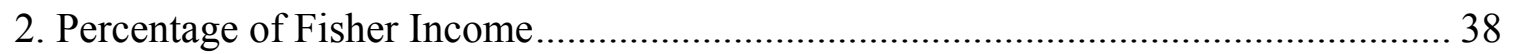

3. Commercial fishers opinion on how they feel the creation of the FKNMS has affected the condition of the species normally targeted, the overall catch, the competition among fishers, size of catch, cost of business, price of catch, and the demand for product......... 47

4. Commercial fishers opinion on how they feel the creation of the FKNMS has affected the condition of the species normally targeted, the overall catch, the competition among fishers, size of catch, cost of business, price of catch, and the demand for product........ 48

5. Shows how commercial fishers feel the condition of species normally targeted, the overall catch, the competition among fishers, size of catch, cost of business, price of catch, and the demand for product would be in 10 years from now, if the FKNMS were to lose all protection.

6. Change in Support of Commercial Fishers Toward the Florida Keys National Marine

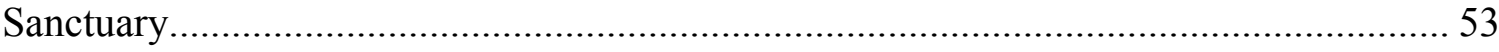

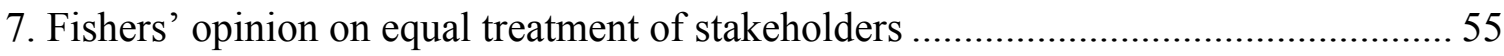

8. Fishers were asked to rank which stakeholders benefitted the most from the creation of the FKNMS 56

9. The support of fishers for more no-take areas in the FKNMS 58

10. Fisher response when asked to respond to the statement, "the FKNMS has been a beneficial tool for managing fisheries". 59 


\section{LIST OF ABBREVIATIONS}

CAC .......................... Command and Control

DAP ......................... Dedicated access privilege

EDF......................... Environmental Defense Fund

FKCFA ...................... Florida Keys Commercial Fishermen's Association

FKNMS ........................ Florida Keys National Marine Sanctuary

FMZ ........................ Fishery Management Zones

FWC ......................... Florida Fish and Wildlife Conservation Commission

IFQ ......................... Individual fishing quotas

ITQ ......................... Individual transferable quotas

MPA …..................... Marine protected Area

NOAA ….................... National Oceanic and Atmospheric Association

SPL........................... Saltwater Products License 


\section{CHAPTER 1}

\section{OVERVIEW AND INTRODUCTION}

\subsection{Introduction}

In any ecosystem, comprehensive long-term management is essential to protect and preserve valuable resources, and this holds true especially for the fragile resources of marine ecosystems. No other ecosystem on earth provides humanity with services quite like the ocean does. Marine resources are some of the most valuable resources on the planet and are in dire need of protection. The marine ecosystems of Earth are being pressured from a myriad of sources. Increasingly eutrophication of estuaries and dead zones, acidification of the sea do to an overabundance of atmospheric carbon dioxide, and devastating oil spills are only a few of the sources. Another prominent threat to the ocean is overfishing. Ecologically, overfishing can alter the marine environment in a number of ways from removing entire trophic levels, to reducing grazing pressure on algae that is essential to maintain coral reefs recruitment and growth. The United Nations Food and Agriculture Organization (UNFAO) reports that $25 \%$ of all fish stocks are overexploited, depleted, or recovering from depletion (Beddington 2007). Close to 60\% of the global population lives on or near coastal regions. Furthermore, $80 \%$ of worldwide tourism is directed to coastal region. The high density of coastal residents and tourists poses the threat of over exploitation of the ocean as a resource. Yet, only $1 \%$ of the total is set aside as 'protected' (IUCN 2009).

To mitigate the effects of anthropogenic pressures on ocean resources, several techniques and strategies are used including, but not limited to marine protected areas 
(MPA). Other strategies include controlling the amount of effort fishers put into a fishery, and ecosystem based management which focuses on the combination of multiple techniques with each of these strategies having its own set of pros and cons (Pikitch et al. 2004, Townsend 2006). This thesis focuses on two of these strategies; the use of MPAs as a fishery management tool, and the use of dedicated access privileges (DAP). Specifically, I conducted a survey to collect information regarding the preferences of commercial fishermen in Monroe County, Florida, United States of America, for various management practices used in the Florida Keys. By identifying which factors are present in the Florida Keys commercial fishery industry for specific management frameworks, more detailed management plans can be drafted. For example, if fishers are more favorable of a specific management framework over another, it might be plausible for managers to explore a similar framework as the data shows there is already a degree of favorability within the industry. Specific factors include the size of the operation, if a fisher is organized, experience, how many species are targeted, and so on. There could be varying degrees of support, or lack thereof, within these factors for current and possibly, future management frameworks. Also, the Florida Keys provides a unique opportunity to study an industry that has, within its boundaries, a very large MPA as well as other management frameworks.

Marine protected areas are known throughout the conservation community as standard means of protecting biodiversity within the larger goal of ecosystem-based management. As is with terrestrial systems, marine areas set apart for protection can have great effects on protecting individual species and communities. And, if properly managed, MPAs can contribute to the overall health of ecosystems (Thur 2010). The 
strategy of using MPAs as a tool for conservation has been at the forefront of several recent conferences aimed at sustainability. Beginning with The World Summit of Sustainable Development in 2002, the Fifth World Parks Congress in 2003, and the Eighth Conference of the Parties (COP8) in 2006, leaders met "to set aside 10-30\% of their waters in MPAs by 2012" (Halperm 2010). In general, from fisheries standpoint, MPAs are designed with the following objectives (Greenville 2007):

1. Reduce the effort of non-optimally managed fisheries;

2. Hedge against uncertainty;

3. Shift biomass towards optimal levels;

4. Influence resource base in multi-species fisheries.

However, MPAs are often quite unpopular with fishermen, as they reduce their fishing grounds. Some studies have shown support for MPAs after a period of time has passed (Shivlani 2006). However, support varies quite a lot across fishers as factors such as age, length of career, fishery, vessel type, number of fishers in a fishery, and numerous other factors all affect support (Dimech 2009, Klein 2008, Pita 2010). Even when allowing fishers to take an active role in the participation of the MPA design, it is unlikely that all fishermen will agree on single set of restrictions. For example, one of the fishers in Scholz's (2004) study stated, "every part of the coast is critical to someone". Therefore some segments of the fishing industry will oppose the establishment of an MPA. If fishers fail to comply with parts of the management plan that focuses on using MPA management, a lack of trust could develop between fishers and management (Pita 2010). Furthermore, MPA style management represents a type of command of control (Holland 2006). Marine protected areas are gaining support among user groups including 
fishermen. However, there is still not a majority of support for MPAs among commercial fishers (Shivlani 2006).

Using MPAs does not necessarily address a main cause of the pressure on fisheries, which is effort put on fishing (Townsend 2006). It is true that effort within an MPAs is reduced, and often eliminated, and that there could be positive effects on the surrounding areas (McClanahan 2001). However, surrounding areas could see an increase in effort putting strain on stocks outside of MPA boundaries. The displaced effort can create what Sumaila (2006) refers to as "winners and losers" of MPA design and implementation. Here, factors such as species targeted, skill, vessel size, and efficiency create a situation where some vessels or firms benefit more than others. However, some researchers believe the industry as a whole is "in crisis", because of declining fish stocks (Minnegal 2008). Therefore it might be plausible to consider an alternative to a command and control (such as MPA style management) framework that gives incentives to fishers to fish less and also give more efficient vessels the ability to fish more than smaller vessels and firms (Pinkerton 2009). An alternative management framework could be to use dedicated access privileges (DAP) which give fishers the privilege to catch a certain percentage of the total allowable catch (TAC) (Holland 2006, Chu 2008). By setting a cap on the total amount that can be harvested and giving a quota of that cap to individual fishers, fishing effort can be reduced, thus easing the pressure on the stocks (Pinkerton 2009). Contrasted with MPAs, quota systems do not simply displace the effort, but reduce it. Some quota systems allow for the trading or selling of the quota to other fishers, firms, or even to fishery managers. For example, if a small owner-operator fisher 
may opt to sell its quotas to a more efficient firm, the amount of fishers in the fishery has been reduced, thereby lowering effort.

Under a total allowable catch (TAC) system, which must be implemented even if MPAs are also used, there exists what is known as a "race for fish". Fisheries, both biological and the industrial, suffer under a TAC system primarily due to overcapitalization within the industry (Tupper 2002). A commonly held belief among fishers is, "if I don't catch the fish, someone else will." This overcapitalization is controlled by implementing fishing seasons which attempt to manage this race and the short length of time it takes to use the total allowable catch. Under a DAP system, the potential for a lengthened season, increased value per weight, and a fresher, higher quality product exists. Also, DAP systems have shown to lower production costs, all the while slowing and, in some cases halting, exploitation of fish stocks (Townsend 2006, Costello 2008).

Individual transferable quotas (ITQs), a form of DAPs do have opponents among scientists, managers, and fishers. Some arguments against ITQ fishery management is that it is considered an economic approach which does not address the biological aspects including "high grading" which is "discarding fish of lower market value to maximize returns from the catch share" (Smith, T. 2009). Further concerns include the fact that no consideration is given to species that cross jurisdictional boundaries as well a putting further pressure on management to enforce compliance to the catch share regulations. In multi-species fisheries (as is common in the Florida Keys commercial fishing industry), movement away from DAP managed fishery to another fishery can put pressure on the newly targeted species. Furthermore, allocating "property rights" may create situations, 
such as protection of benthic habitat, that become more difficult to manage (Smith, $\mathrm{T}$. 2009).

\subsection{Florida Keys Fishing Industry}

The Florida Keys National Marine Sanctuary incorporates 2,900 square miles of the Florida Keys archipelago. The industry itself supports 1200 families targeting a variety of species which includes spiny lobster, stone crab, reef fish, and shrimp. The Monroe County port is considered one of the most valuable in the United States with the dockside value of product caught (excluding shrimp) being \$54 million. In 2009 Monroe County was ranked the fifth most valuable in the United States and is consistently rated in the top ten ports for the last twenty years. This port also boasts the largest commercial fleet from Texas to North Carolina. Furthermore, $80 \%$ of all spiny lobster captured in Florida, comes from the Florida Keys (FKCFA 2010). However, the industry in the last twenty years has seen a reduction in poundage caught as well as a drastic reduction (about 53\%) in the number of saltwater products licenses (SPLs). Currently, there are approximately 1200 SPL holders in Monroe (FKCFA 2010). The preliminary fisheries landing data from 2010 show that nearly five million pounds of finfish and six million pounds of invertebrates (excluding shrimp) were landed, making the Monroe County port the most productive in the state (FWC 2011).

In June of 2009, NOAA created a task force with the purpose of developing a plan to impellent DAPs throughout the individual fishery regions in the United States. The plan went into effect in 2010 and "encourage[s] the voluntary use of well-designed catch share programs in appropriate fisheries to help rebuild and sustain fisheries" (NOAA 
2009). Currently the studied region (South Atlantic) has only one species (wreckfish) under the NOAA catch share program. This research will help designers to create those well designed programs by allowing them to focus resources on the areas of interest that are revealed through this study. Furthermore, a baseline for future studies will be created to determine change in perceptions from any policy changes. Commercial fisher experience with marine protected areas and recent discussions of implementing dedicated access privilege frameworks allows for the testing of hypothesis built around fisher perceptions of alternative management frameworks. The fisheries located in the Florida Keys are some of the most profitable in the country. Understanding how fishers believe the implementation of management frameworks affects them is an important step in ensuring the profitability of the industry continues.

\section{CHAPTER 2}

\section{LITERATURE REVIEW}

\subsection{Marine Protected Areas}

In the early 1990's, marine protected areas (MPAs) became an increasingly used tool for conservation, as well as a mechanism for reducing fishing effort and in turn, increasing fish stock. Polacheck (1990) showed that MPA's can increase spawning potential. Furthermore, it has been shown shown that spillover from protected areas can and does happen, sometimes improving fisheries in areas adjacent to MPAs (McClanahan 2001). 
The range of services provided by MPAs is well known (conservation, recreation, enhanced ecological services), but the closure of fishing ground is also expected to have some negative economic effect. When an MPA is created it is assumed that effort for fishing will be redistributed (Smith 2003). What is not known though, is how a closure will affect societal welfare in a particular area (Glenn 2010). One way to determine this connection is to continuously evaluate an MPA for these societal benefits. Many times a reserve is established and fails to meet its goals. Adaptive management is key to reestablish protocol and get back on track. One way to determine if MPAs are an effective tool for fishery management is by analyzing fishery data. However there are some problems associated with relying solely on fisheries data. Smith (2006) argues that fishery data (catch) may not necessarily indicate a productive reserve. He argues that there could be a decrease in effort or displacement of less skilled fishers to areas of no fish. This is what is called being a "winner" or a "loser" associated with MPA management scheme. Winners and losers can be predicted by analyzing related factors such as vessel/gear type, or the skill of the crew (Sumailia 2006). Ultimately, stakeholder participation and fishers' perceptions are critical to understand what the impact of an MPA may be. It also allows for incorporating fishers' concerns into a productive and efficient management strategy.

Studies have shown that MPAs are used as fishery management tools, albeit with mixed results. Determining the extent to which MPAs contribute to fisheries is a little more difficult because the way fisheries benefit from MPAs may differ. McClanahan (2001) showed that with increasing age of a marine protected area, fishermen placed traps further and further from the border of the protected area showing the effect of spillover. 
Often, fishers congregate at the borders of MPAs to take advantage of spillover (Stelzenmuller 2008). In a predator-prey, open access fishery, an MPA was linked to and improved fishery (Greenville and MacAuly 2006). In a single species fishery, when the surrounding stocks are considered low, that fishery was bolstered by a marine protected area (Sanchirico 2001, Wilen 2001). However MPAs do not guarantee collapse prevention though, but could act as a buffer against stock collapse (Lauck et al. 1998, Conrad 1999).

\subsection{Dedicated Access Privileges}

In contrast to command and control style of MPAs and TAC, are dedicated access privileges (DAP which is a form of an incentive-based approach. It should be stated that incentive-based practices are inherently more challenging than command and control (CAC) management. Dedicated access privileges require extensive and constant monitoring of the fishery at all levels from basic amount harvested to the quality captured. In Figure 1, it can be seen that high management costs are needed if the overall effort is to be brought below the maximum sustainable yield (MSY), creating a sustainable fishery (Schaefer 1959). 


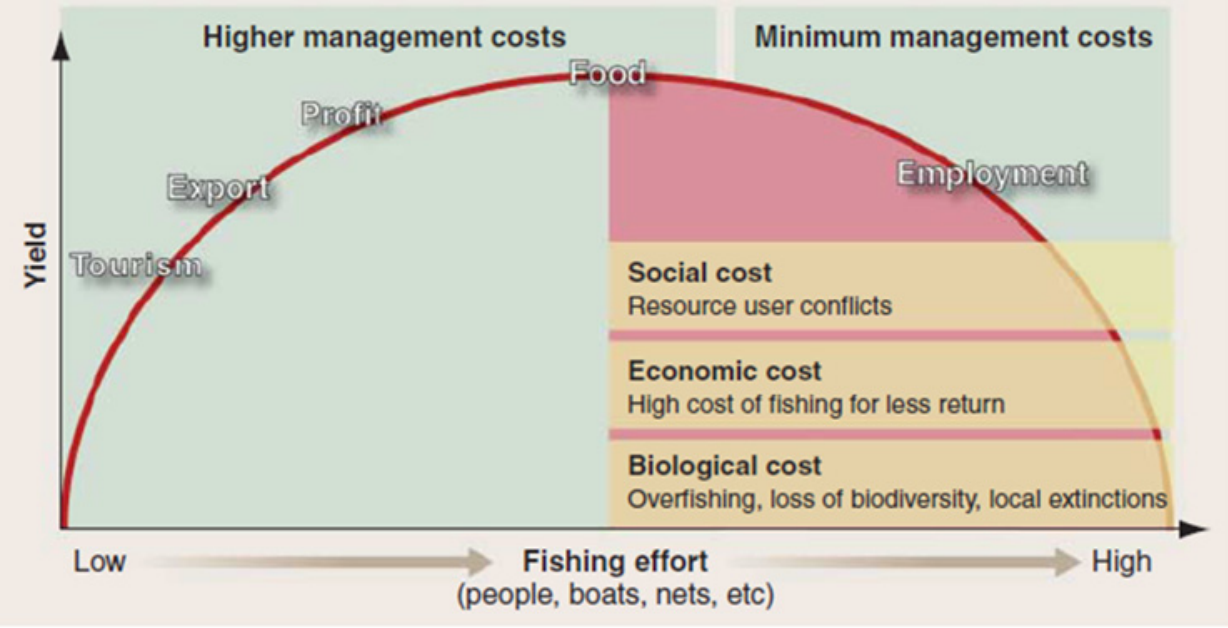

Figure 1. The Gordon-Schaefer model shows the result of increasing effort on a fishery. Problems (social, economic, and biological) are realized when the effort increases beyond a threshold (Beddington 2007).

Incentive-based systems can come in many different forms, with the common, underlying theme being that fishers are given freedom and flexibility to choose what individual level of effort they want to put into fishing. The term that being used to describe the basic and most commonly used incentive-based program is Limited Access Privileges (LAP) or Dedicated Access Privileges (DAP). Dedicated access privileges in this study are described in many different ways. Individual fishery quotas (IFQ), individual transferable quotas (ITQ), and individual habitat quotas (IHQ) are all forms of dedicated or limited access privileges. The term dedicated access privilege was derived to provide a broad sense of the many forms of incentive-based programs. By assigning de facto "property rights", more control can be given to the managers to operate on a more efficient level. By "privatizing the commons" a slew of problems (transferability, open access, "derby style" fishing) can be brought under control. The basic components of property rights of duration, exclusivity, and transferability are all practices that seek to 
bring rent seeking and over capitalization under control (Gibbs 2007). However problems arise when property rights are assigned when considering that fisheries are public goods owned by the American people (United States). Once property rights are assigned, it becomes more difficult to take them away (Macinko 2003, Bromley 2004). Having the ability to take away quotas, thus reducing effort, is essential when managing a fluctuating stock. Fishers are allocated permits that give the fisher the privilege to harvest a certain portion of the harvest (SAFMC). When open access fisheries are non-exclusive, fishers have no reason to conserve the resource (Copes 1986). With the allocation of permits that allow fishers the privilege to harvest a specified portion of the total harvest, the fishery can be rationalized. According to the Magnuson-Stevens Act, the state owns the fish but can allocate rights (privileges) to harvest the fish, similar to giving property rights (Edwards 1995, Macinko and Bromley 2004). Dedicated access privileges are designed to reduce effort, increase safety and allow fishers to take a larger stake in the management of the fishery (Holland 2006, Townsend 2006, Chu 2008). Furthermore, by simply implementing a DAP system the probability of collapse is reduced (Costello 2008).

Depending on factors such as size of the fleet, species targeted, and area fished, DAPs can be allocated in different ways and having different stipulations attached. One form of DAPs are individual fishing quotas (IFQ) commonly known as "catch shares" (for the sake of clarity here, IFQs and catch share will be considered non-transferable unless otherwise stated). Once distributed, IFQs are designed to stop or, at the very least, slow the race for fish. The benefits that DAPs can have on an industry seem to be significant but there are concerns, specifically within the industry itself. Fishers have 
concerns about the details of DAPs including the initial allocation, stratification within the industry, and fees that are tagged to the permits (Pinkerton 2009).

To mitigate possible improper allocation of permits, another form of DAPs called individual transferable quotas (ITQs) or transferable catch shares, gives additional flexibility within the industry by allowing fishers to sell, lease, or buy (Chu 2008).

Another form of DAPs are individual habitat quotas (IHQs) which serve to mitigate damages done to the ecosystem caused by fishing. Both IFQs and ITQs focus primarily on single species management. Individual habitat quotas (IHQ) consider the spatial aspects of fishing. For example, given a particular habitat, lobster fishers may only place so many traps in that area but may place as many traps as they wish in other areas (Holland 2006). Finally, managers may try to reduce effort by simply "buying out" the fishing privileges. Similar to a land agency purchasing farmland in which usual practices conducted on that land may harm adjacent ecosystems, the industry can be simply paid not to fish, thus reducing effort (Minnegal 2008).

When considering implementing a DAP framework, managers have to be mindful of the effects, both positive and negative, that can occur. Dedicated access privileges have seem to replace command and control frameworks such as limited entry fisheries as the new alternative to the more traditional total allowable catch regimes (Dewes 2009). The change from TAC to alternative management practices signaled and important shift in fisheries management, when it was noticed that input style measures could not effectively end the "race for fish" (Criddle 2000, McCay 1998). Beginning in the 1980's and continuing into the 1990s, several fisheries underwent the change into a DAP framework. The Mid-Atlantic surf clam fishery (MAFMC), the Atlantic wreckfish 
fishery (SAFMC) and the Sablefish fishery in the Pacific (NPFMC) were among the first fisheries in the United States to adopt such dedicated access privileges. These fisheries adapted dedicated access privileges because of the overcapitalization of the fleet within them.

Overcapitalization of the fishing industry is seen as one of the biggest deterrents to achieving sustainable fisheries (Tupper 2006). Overcapitalization leads to "derby style" fishing. For example, under a TAC system that is overcapitalized, once the TAC is met, the season is closed. Essentially, excess capacity in TAC frameworks lead to compromised seasons (Criddle 2000). The compromised seasons could also lead to an overall diminished situation for the industry as a whole. The goal for managers then turns to reducing the overcapitalization within the industry, which in the process, reduces fishing effort.

Marine protected areas, moratoriums, and gear restrictions have all been used to reduce overcapitalization. Dedicated access privileges are a blunt economic tool to manage fisheries, relying on a decentralized market to work efficiently. The recent popularity of using an incentive-based approach to fisheries stems from managers' relative dissatisfaction in traditional fishery management frameworks (Costello 2008). It is then argued by some that DAP systems could be the best way to "organize activities" (Gisurratson 1999). It is also stated that DAP systems increase the flexibility of fishers who now do not have to be concerned about competing in a derby style fishery (Criddle 2000).

An example of the effect that ITQs can have on fishing effort within an industry and the fishery it targets is seen in the North Pacific salmon fishery (specifically the 
Chignik Salmon Co-op). This limited entry fishery with tradable quotas saw a drastic change within the industry when the program was implemented. The fishery had 100 open, active permits which were completely transferable. However, on average only 20 permits changed hands within a season. The industry decided to form a co-op with 77 permit holders deciding to consolidate and 23 members opted to remain independent. The co-op was allotted 69 percent of the total permits with the other 31 percent given to those who remained independent. To maximize gain for the co-op, only 22 members were responsible for catching the total percent of the quota given them. After the season fishers reported there being less competition among the fleet, as well as there being an overall more enjoyable fishing experience due to the reduced fleet size. Furthermore, the industry as a whole was able to remain profitable, even with the total reduced effort (Costello 2008).

Grafton (1995) shows the response of fisheries after the initial allocation of quotas in several fisheries that adopted such frameworks. The British Columbia sablefish fishery saw a reduction of 16 vessels from 46 to 30 in just one year. In Lake Erie, after five years, the fleet had been reduced to 182 vessels from the initial 248 (Cowan 1990). In the Australian bluefin fishery, a 49 percent reduction of the fleet was observed in only four years (Muse and Schelle 1989). However, it is noted that the effects of DAPs may not be felt for several years (Grafton 1996). The New Zealand squid fishery saw an initial spike in the number of vessels in the fishery. The same thing happened in Iceland where a fishery did not see a reduction in vessels, however did notice a reduction in overall effort (Arnason 1986). 
For an ITQ system to be effectively implemented, the market assumes several conditions to be met. Two stipulations for this are the homogenous nature of both the fish stock and the composition of the industry. Costello (2008) points out that if these conditions are not met, all rents in the industry may not be secured. It is argued that without spatial separation (i.e. heterogeneous stock) several fishers may be disadvantaged. For example, fishers prefer stocks that are close to a port. By fishing close to port, the costs of fishing are reduced in the form of opportunity costs and fuel costs as well as other costs that are associated with fishing far from port. Fishers who are able to fish more effectively at these conveniently accessible stocks would push other fishers within the industry to least accessible stocks further from port raising fishing costs. If the goal of ITQs is to bring down the costs of production, then certain conditions will have to be met or managers and the industry will have to decide on possibly implementing spatial rights to access the fishery (Costello 2008). Basically if the fishing ground is congested, there could be higher costs for related sectors of the industry (Boyce 1992).

\subsection{Drawbacks of Dedicated Access Privilege Frameworks}

In the mid 1990's, as DAPs were being implemented more frequently, there existed several inherent problems with DAPs that caused managers and policy makers to reconsider this framework. When the Magnuson-Stevens act came up for renewal in 1996, a moratorium was placed on any further implementation of DAPs, due to the fact that it was observed that the use of such policy was "prone to serious defects" (Dewees 1992, Criddle 2000). 
Copes (1986) states that it should be expected that more efficient operations will end up with the majority of quotas (when the quotas are transferable). By doing this, a firm or firms may be able to buy up quotas and then hold them as market power. Traditional market power comes in two forms, the ability to control production and the ability to restrict supply. In an ITQ fishery, the market power comes from the ability to restrict supply by not allowing other operators to fish. To combat this, managers often place restrictions on what percentage of the total allocations can be acquired by one individual or firm. For example in the Florida Lobster Trap Certificate Program (LTC), no individual may obtain more than 1.5 percent of the certificates (Shivlani 2000). However this prevents the true price of the product from being realized. However by buying too many permits and controlling how much product to be released, the price may actually be pushed higher than the willingness to pay by the consumer. It is therefore argued that only in special cases and in specific fisheries, a "monopoly limit" may not need to be stipulated (Anderson 2008).

When used alone, ITQs have been criticized as not addressing some of the main concerns of fishery management, including the limitation of focusing on one fishery at a time. Critics have referred to ITQs as narrowly focused policy instruments that ignore the crucial element of ecosystem based fishery management (EBFM) (Smith, T. et al. 2009). For an ITQ system to work as an effective component of EBFM, several criteria have to be met. First is the fact that the overall total allowable catch has to be set below the maximum sustainable yield (MSY). Setting the TAC below the MSY will in turn allow the population that is targeted to rebound in subsequent harvest seasons and is less likely to have major impacts on trophic levels the species interacts with. Also by setting the 
TAC below the MSY, the fishery will produce larger harvest in the future. Secondly, the allocations of permits have to reflect market price. Signals from the market should be considered when allocating permits as to keep the industry relatively stable. And finally, the industry has to take deliberate action to reduce effort or the process will fail to work as planned (Gibbs 2007).

When a fisher is given the "right" to harvest a specific amount of the TAC, it is understandable that the fisher wants to get the most from his catch. If a fisher cannot fish over his limit, he is looking for the best quality catch, which is referred to as "high grading”. High grading is when a fisher will discard less profitable fish in order to be able to keep fishing for higher quality fish for maximizing profit form the total catch.

Furthermore, high grading has the potential to severely undermine the goals for managing a stable fish stock. Fish discarded represent fish that could be caught by others, thus having a negative impact on the fishery as a whole. Stock assessments require constant monitoring in order for a proper TAC to be set. If discarded fish go unreported, then stock assessments could be incorrect. A way to combat this is by placing observers on vessels paid for by fees included in the quota price. Not only can discarding be monitored, but a more accurate assessment of the fishery can be made (Branch 2006).

\subsection{Fisher Perceptions of Marine Protected Areas}

Dimech (2009) reports attitudes and perceptions of fishermen across all types (commercial, recreational, and part time commercial) for a 35 year old marine reserve. The objective of the marine reserve was to protect the area's fisheries, which have an enormous economic impact on the surrounding region. The study finds that across all 
sectors there was a general attitude that the marine reserve had failed in its stated purpose. However there were marked differences across different types of fishers for the reason causing failure. Some of these differences were the result of fishers that targeted specific fisheries. Mainly, attitudes towards the fishery management zone (FMZ) became harsher. Species that have a higher vagility and stayed in the FMZ for a short period were less protected. It was fishers who target these species that perceived the FMZ to be a failure the most. As the species became less vagile, the fisher's attitude followed and became less harsh. In addition older fishers did not like the FMZ because it made them fish further from shore. Since the beginnings of their career, near shore fisheries had been fished out and the FMZ had not replenished those stocks in their eyes. Empirical data backed up this claim by showing an increase in landings further form shore (Dimech 2009). Secondly, attitudes seem to differ among vessel size however European Union (EU) regulations confounded results. Finally the perception of the FMZ was that there was an overall positive contribution to the local economy, however for fish stocks, this was not the case Dimech 2009).

Attitudes of the management of the FMZ varied among socio-demographics as well as including by type of fish targeted. When considering support for the management, it seemed to be correlated with what type of benefit the fisher received from the fishery management zone. When perceived benefit was high, management support was high and vice versa. It can be argued that a stakeholder that perceives management favorably is more likely to comply with regulation and is more likely to report illegal activity. Combined with that, favorable views can lead to a better understanding by the 
stakeholder if new and different policies need to be enacted. The opposite is also true as unfavorable opinions could hamper future policy implementations.

Often times, fishers are opposed to marine protected areas. However, using their knowledge could lead to a variety of opportunities for management. First, incorporating fishers could lead to an overall larger participation in the process. Furthermore, larger incorporation could mean more fishers with an awareness of management goals, rules, and regulations. However, it is unlikely that $100 \%$ participation will occur or even that a general approach could be decided on. Fisher perceptions should not trump the overall goal of an MPA, which is to protect biodiversity, oftentimes in critical habitat. Fisher knowledge is a component in the process as a whole which can be used to list a series of less disputed alternatives for management to take and lead to specific grounds to consider for protection (Scholz 2004).

The goal of different fishery management approaches is to basically reduce the overall fishing effort and to give the targeted species some relief from harvesting pressure and potentially rebound to sustainable levels. With the overall reduction in fleet numbers as a management tool, it is probable that there will be resistance among fishing community. The challenge is to reduce the intensity so that management strategies can properly be implemented.

A way to reduce possible resentment of fishers is to provide an alternative to fishing for members of a specific fleet. Furthermore it can be argued that perceptions of a particular management strategy (i.e., MPAs) are strongly correlated to the opportunities that exist outside of the fishing realm. Smith (2010) shows that the support for a proposed MPA can be measured by how well the job market is outside of fishing. Furthermore it 
can be further divided by fisher skill, length of career, and fisher type (recreational, part time commercial etc.) to how much support exists for marine protected areas. Also the paper indicated that timing (job opportunities) could and should be considered when and where to place marine protected areas. It depends on, however, what kind of opportunities beyond fishing and to what extent alternative stocks are available and at what costs. It then highlights that there could be beneficial long term gains that eventually offset short term loss, but it is noted that there are many factors that have to be considered and are likely to be unknown at the time of creation (Smith 2010).

Pita (2010) discusses the need for stakeholder participation (conflict resolution, establishing relationships, policy participation etc.) but states that not all stakeholders are treated equal and that there might not be equal participation. Furthermore she defines the difference between active and passive stakeholder participation, passive being informed of the policy, not directly involved in policy formation, though passive participation could be a step into more active participation.

Like most studies on this subject, differences in demographics, income, and gear type play a role in support of management strategies. The perceptions of fishers from this study are that they are in favor of some form of management strategies. However, based on past experiences, the management strategy they most prefer will never materialize. Furthermore, if fishers were consulted on previous policies, and those policies were implemented, then that group showed more resistance to any new policies being implemented. They felt it was a departure from strategies that were derived from them being previously consulted and that management was turning their backs on them (Pita 2010). The synthesis from this study is that increased stakeholder involvement does not 
necessarily create "enhanced legitimacy" of implemented policies. However, the increased transparency and increased knowledge of rules by fishers is a big win for management.

In a study by Klein (2008), it was shown that fisher knowledge can, and does play a critical role in designing the most efficient reserves in terms of preserving biodiversity as well as minimizing impacts to their community. Fishers possess the exact knowledge of represented biodiversity fishing effort across spatial scales. Fishers input can also be used in minimizing impact to fisheries in the reserve design process. Using their knowledge, fishers designed the most efficient reserves across all groups, revealing, or by now, enforcing the notion that fishers play critical roles. Combined with the results from other studies, it is shown that joint efforts work the best when designing reserves.

After an MPA is created, monitoring fisher response by studying behavior can be valuable information. Where fishermen fish, and which socio-demographic characteristics among fishers is fishing a particular area in response to a closing, can play roles in the formation of future policy and management directions (Suuronen et al. 2010). Furthermore if behavior is not well documented, current and future conservation goals could be hampered.

A study focusing on a series of spatial closures in the Baltic Sea and the fisher response showed that those fishers faced hardships as a direct result of the closing of a certain area (Suuronen et al. 2010). Fishers stated that due to the closure, they were pushed into other fishers' territory, the MPAs were ineffective at increasing stock, and also of increasing competition among fishers from the same area. Furthermore, fishers argued that the closure protected a highly mobile fish and that in itself failed to protect 
the fish from harvest. Another complaint was that the fishing grounds left were of poor quality (Suuronen et al. 2010).

\subsection{Fisher Perceptions of Marine Protected Areas in the FKNMS}

Shivlani (2008) reviews attitudes and perception in the FKNMS after ten years of creation. Many of the factors discussed in this study reflect those mentioned in the previous studies, which gives a good overview of the fishery and establishes a new baseline for the region. The main finding is that the overall opposition among commercial fishers is lessening in ten years since implementation. It was noted that in the previous study (Suman et al. 1999) opposition to the FKNMS was higher, citing that conditions (restrictions, placement of zones, amount of area off limits, etc.) of the reserve were predetermined.

Overtime, opposition from commercial fishers has decreased in spite of the feeling that the particular zoning strategy implemented by the reserve's governing body the (National Oceanic and Atmospheric Administration, NOAA), has not really succeeded in enhancing fisheries. They did however agree that, one main reason for such opposition is that they believed penalties issued by NOAA would not be fair and just. The view now is that NOAA has in fact been fair and just in enforcement. Commercial fishers still remain wary of the process in which NOAA implements policies, but not as much as the previous study. This is attributed to the transparency in which NOAA implements MPA management.

In general, it has been found that there has been no significant impact to the commercial fishing industry in the FKNMS. However, in agreement with the above 
studies, the commercial fishing sector has undergone some changes. First, there has been a major reduction of salt water products licenses (SPL) of 53.1\%, indicating that effort has been displaced or reduced altogether. This could present fishers remaining in the industry with that "winner" situation. Another analogy to previous studies would be proposing fishers with outside employment opportunities leaving the sector (Smith 2010). The data reveals that a higher percentage of the sample to be more professionalized (fulltime) than in the previous study. Furthermore, fishers in the present study (Shivlani 2006) are said to carry on average more gear than before.

\subsection{Fisher Perception for Incentive-based Management Frameworks}

Though the use of a DAP system can be beneficial for a stock as well as, in certain cases, for the industry, DAP frameworks including ITQs can be met with skepticism and hostility from the industry. The basic premise of a transferable quota system is that there will be an aggregate gain for the industry and as well as an aggregate distributional effect. One key concern is that fishers' positions within the industry, including the economic power, can be negatively affected in addition to losing bargaining power and loss of employment as the fleet is reduced (Branch 2006, Brandt 2005).

The Mid Atlantic surf clam fishery is a $\$ 48$ million industry is responsible for a large percentage of clam based products such as canned clam chowder. Traditionally this fishery was managed by a total allowable catch system. In 1979 the average vessel spent 36 hours a week fishing. By 1984, with the fishery declining, vessels were spending an average of 6 hours a week fishing. When the proposal of an ITQ system was first suggested it triggered an even further decline of the fishery. The details of the ITQ were 
released saying that permits were going to be allocated by vessels, not by the owner. Specifically, allocations were to be based $80 \%$ of historical catch with the remaining $20 \%$ based on the holding capacity of the vessel. Suddenly, vessels that were licensed to operate in the fishery but not previously in use due to the low economic gain from fishing were rushed into action to increase allocations for the owners. This significantly increased effort on an already strained fishery.

When the new framework was fully implemented, a study by Brandt (2005) was conducted to see what effect the ITQ system was going to have on the industry keeping in mind the concerns of the fishers that the new system would disadvantage them both socially and financially. The reason behind these concerns is that vessels that were well funded and more efficient would out-compete smaller owner-operated vessels, stratifying the industry. However, it was discovered that after implementation, several smaller operations consolidated and not losing their standing within the industry. In fact it was discovered that several consolidated operation actually increased their standing within the industry.

Another example of concerns of a DAP system comes from the spiny lobster (Panulirus argus) fishery in Monroe County in South Florida. In 1991 a DAP system was implemented focusing on trap limitations. The Lobster Trap Certificate Program (LTC) was used to stabilize the market as well stating that over time the number of traps in the water would be reduced. After the program began, fishers were asked to give their perceptions on the program. It was discovered that the majority of the fishers were against the program. However, not surprisingly, the percentage of larger operations in favor of the program was greater than those of smaller operations (Shivlani 2000). As a 
whole the industry disapproved the way this program was implemented. Citing several reasons for their disapproval, two major concerns were the fact that the program allowed for speculators and outsiders to purchase permits and then lease them out. They felt like this was a plan of management to make money off of the program. Although fishers stated that leasing has allowed for smaller operations to remain in the industry as they cannot afford to purchase certificates. Another major concern was the changing social landscape they felt was happening within the fleet. The previous social structure of the lobster fishery in the Florida Keys was based on the practice of apprenticeships. For several years an apprentice would work under a mentor and then would take over the operation when the mentor left the industry. The majority of those sampled felt that this practice was being phased out because of the fact that young fishers were unable to afford certificates (Shivlani 2000).

A review of the Alaskan Halibut fishery provided keys insights into how fishers view dedicated access privileges. A fishery quota system was experimented with in the early 1990s and was fully implemented after the trial process. Quotas were allocated based on a seven year time frame that considered the best five of those seven years. The study takes a unique perspective by asking both those who received the quotas and those who don't, to comment on the perceptions they had concerning their future financial situation. The outlook the industry had on the future was grim. Of those surveyed, only $23 \%$ felt they would be better off financially than under the old framework. Furthermore, only $29 \%$ preferred the DAP system over the current system and only one fifth of those sampled believed the allocation of quotas would be fair. This study showed a large 
amount of distrust within the industry of any measures to reduce effort by dedicated access privileges (Knapp 1996).

Fishers in the Finnish herring fishery conveyed similar concerns in implementing dedicated access privileges. While they understood the need for the fishery to be managed, there were reservations about how exactly DAPs could benefit those within the industry. The Finnish herring fishery presents an interesting scenario because the industry, as a whole benefitted from the use of a limited access framework. The profitability (as a whole) of the fishery increased, the product was of better quality, fishers reported less competition, and the price of the product increased as well. However the change in the dynamics of the industry is what concerned those belonging to this fishery the most (Kulmala 2007). They noticed that quotas were being concentrated on the most efficient vessels. It was also stated that quotas should not be allocated to individuals or firms that were not professional fishers. Concerns of a growing market and an increase of middlemen could possibly drive up the price of quotas, disadvantaging less funded fishers. And finally, many expressed that they had reservations about the ability of the quotas to be transferred among fishers (Kulmala 2007). In summary, fishers are concerned with the effects that DAP systems could have on their fishery including the social, financial, and political structure within the industry. Fishers are less concerned with the aggregate gain as some fishers, mainly small operations could potentially be pushed out if they do not restructure. 


\section{CHAPTER 3}

\section{RESEARCH METHODS}

\subsection{Research Objectives}

Against the backdrop of the Florida Keys commercial fishing industry, this study evaluates the perceptions and attitudes of commercial fishers concerning views on the notake areas in the Florida Keys National Marine Sanctuary. While the results from this study will provide a third baseline for the region (Shivlani 2006, Suman et al. 1999), perceptions for the various no-take areas in the FKNMS as a fishery management tool can also be determined. Also, perceptions of fishers for incentive-based fishery management frameworks are examined. While the FKNMS was not originally created for the specific reason to increase fishery yields, part of its management plan was to provide areas free from harvest (FKNMS Draft Management Plan 1994). Having areas free from harvest could potentially benefit various fisheries in the Florida Keys. As shown in the literature review, many studies have shown the benefits that MPAs can have on surrounding fisheries. One area this study focuses on are fishers' views regarding the notake areas in the FKNMS as fishery management tools.

The other area of focus of this study are the perceptions of fishers for a DAP framework. Currently, there are DAP systems in place for the trap lobster and stone crab fisheries in the Florida Keys ecosystem (Shivlani 2000). Most fisheries, however, are managed through total allowable catch. Specifically, this study investigates which groups of Florida Keys commercial fishers are willing to have a DAP system implemented. The literature shows that the use of DAPs can drastically alter fleet dynamics, specifically in 
the form of fleet reduction. Fishers who stand to benefit from the implementation of dedicated access privileges may be more supportive of such a framework. Furthermore, it has been shown that individual sectors of a fishery can vary quite significantly in their support of management issues, and a DAP managed fishery is no different (Shivlani 2000). Support for DAPs can be determined through fisher age, length of career, and crew and vessel size, which could be an indication of the size of operation. This study aims to identify fisher characteristics and the likely hood of support for alternative management frameworks.

Shivlani (2000) surveyed lobster fishers to gather their opinions on the Lobster Trap Certificate program, seven years after inception. It was discovered that large operations capable of purchasing and holding significant amount of certificates approved the program. This was in contrast to small operators who viewed the program as a failure. Shivlani (2000) agreed with the findings from other studies suggesting that smaller operators would be pushed out of business (Brandt 2005, Pinkerton 2009). Fishermen have been surveyed to show that more traditional alternative management (i.e., TAC) is somewhat preferred than incentive-based measures (Roberts 2001). Furthermore, the social issues raised by implementing DAP systems are a major concern for fishers and for other members of the industry alike. Some issues raised include distribution of initial allocations, stratification within the industry, and the loss of access privileges for less funded operations (Ban 2009). My study evaluates fisher opinions on implementing a DAP framework in their particular fishery. In addition the study also focuses on identifying which fisheries would be more or less supportive of an incentive-based 
approach to management. Individual fisher characteristics (gear type, vessels length etc.) within each fishery can also be identified.

\subsection{Hypotheses}

Hypothesis 1: The fishing industry as a whole will not support a dedicated access privilege approach to fishery management in the Florida Keys.

Hypothesis 2: Large operations/firms are more likely to support an incentive-based management approach to fisheries.

Hypothesis 3: Organized fishers are more likely not to support dedicated access privilege frameworks.

\subsection{Data Collection}

Data were collected through a survey during April 13, 2011 through Aug 1, 2011. All holders of Florida Saltwater Products Licenses (SPL) from an obtained database were contacted and given the opportunity to participate in the study. The database was obtained from the Florida Fish and Wildlife Conservation Commission (FWC). The database contained at the time (December 2010) names, addresses, emails of 948 SPL holders.

In order to collect information about fishers' preferences about different management practices, a structured survey was designed. Earlier research papers related to this issue (Suman et al. 1999, Shivlani 2000, 2006) were extensively reviewed in designing the survey instrument. There were two distinct sections of the survey. The first section asks fishers regarding their perceptions of the no-take areas within the Florida Keys National Marine Sanctuary as a fishery management tool. Several questions were 
included to understand their opinion about the FKNMS as a whole. Furthermore, more specific questions were asked to determine their opinion of specific aspects of the sanctuary. These questions cover perceptions of individual management areas, i.e., the ecological reserves, sanctuary preservation areas, and research only areas. Respondents were also asked to give their opinion on how the sanctuary affected a series of criteria including the species normally targeted, the overall catch, competition among fishers, size of the catch, cost of business, price of the catch, and the demand for the product.

Similar to the question above, respondents were asked to express their opinion about how the absence of the FKNMS would affect the same criteria mentioned above. Respondents were asked to evaluate the same criteria if the FKNMS were to lose all protection and cease to exist. Finally, fishers were asked about the likelihood of leaving the commercial fishing industry, which, as stated earlier, could be an overall indicator of the state of fisheries in the Florida Keys.

The second section focused on the fishers' response of the fishers to alternative management practices in the form of dedicated access privileges. Dedicated access privileges can be classified several ways. A non-transferable DAP, which allocates a certain percentage of the total allowable catch to individual fishers/firms, in this study is referred to as an individual fishing quota (IFQ). Similarly, transferable DAPs, which are individually allocated quotas that can be traded or transferred, are referred to as individual transferable quotas (ITQ). Given the differences between the types of DAPs, questions were included to understand preferences regarding different types of dedicated access privileges. Fishers were asked to opine on non-transferable individual fishing quotas, as well as on fully transferable individual transferable quotas. More detailed 
questions of each type of DAP were asked in regard to their potential impact. For example, some questions asked the opinion of the effect DAPs (all forms) would have on the industry, while others focused on the impact of DAPs on the fishing season and the potential to increase the season.

In the subsequent section, the questions shifted focus slightly to ask the fishers perceptions on alternative management frameworks not isolated to DAPs. For example, the survey asked specifically about buffer zones around the no take areas in the Florida Keys National Marine Sanctuary. Also in the section, fishers were asked to rank a series of management frameworks in order of most preferred to least. The ranking question is listed below.

41 Please rank in order the management framework you would like to see in your particular fishery. (1-most preferred and 8-least preferred) Individual transferable Quota System Increase the number of no-take marine protected areas Limit the number of recreational fisher permits Reduce the quota for commercial fishers Reduce number of commercial fishing licenses A non-transferable Dedicated Access Privilege (DAP) system Reduce length of fishing season Restricted gear use (i.e., reducing total number of pots, lines in the water etc.)

The last section in the questionnaire included several demographic questions, as well as questions pertaining to the particular aspects of the industry. Questions were asked to describe vessel size, the number of vessels owned, income, and the number of members in the household. These types of questions were particularly important because the objectives of this study is trying to identify which factors lead to support of specific management frameworks in the Florida Keys fisheries. Other identifying characteristics 
that came from this section include the number of fishing trips per week, status of fulltime fishers, experience, and if the respondents were members of any local, regional, or national fishing organization.

The survey was divided into five sections with a total of 61 questions. Table 1 shows the structure of the survey.

Table 1. Description of Survey Structure

\begin{tabular}{|l|l|c|}
\hline \multicolumn{1}{|c|}{ Section } & \multicolumn{1}{|c|}{ Description of Section } & $\begin{array}{c}\text { Number of } \\
\text { Questions }\end{array}$ \\
\hline Section one & Operation Characteristics: & 8 \\
\hline Section two & Management Framework in the Florida Keys & 17 \\
\hline $\begin{array}{l}\text { Section } \\
\text { three }\end{array}$ & Opinion of Alternative Management Framework & 17 \\
\hline Section four & $\begin{array}{l}\text { Description About Yourself and Fishing } \\
\text { Operation }\end{array}$ & 14 \\
\hline Section five & Demographics & 5 \\
\hline
\end{tabular}

\subsection{Survey Implementation}

The survey was reviewed by a number of key individuals and groups involved with various aspects of management in the Florida Keys. The survey was first sent to the Florida Keys Commercial Fishermen's Association where it was reviewed by the association's board. However, to be well rounded and as objective as possible, other groups were also contacted that favored more conservation actions for fishery management. One of the groups was the Environmental Defense Fund (EDF). The contact at the EDF put me in touch with people who had specific knowledge of the economics and survey design of fisheries and their fishers. The consultants I was put in touch with were an organization called CapLog Group in California. Two separate conference calls were set up to discuss the content of the survey. What we mostly 
discussed were phrases and wording that could possibly confuse fishermen and lead to frustration. Some members were able to provide valuable insight due to their former profession as a commercial fisher. Another result of the calls was a more consistent survey related to abbreviations. Having a consistent format for abbreviations allowed those surveyed to respond to the questions in a more efficient way, creating an easier to understand instrument, which is crucial when collecting the large amount of data needed to complete the study. Other members providing key insight into the survey design and composition were members of the National Oceanic and Atmospheric Administration and members of the Florida Keys National Marine Sanctuary Advisory Council. Both organizations provided clarification of specific aspects of management including the DAP specifics and FKNMS purpose respectfully.

\subsection{Survey Creation and Distribution}

The survey was created and distributed using the survey software, Qualtrics ${ }^{\circledR}$. There were a total of 948 names provided by the Florida Fish and Wildlife Conservation Commission who were holders of saltwater products licenses (SPL). Of those 948 license holders, 407 had emails listed and the survey was distributed to them via email. Nine emails were found to be not working so a total of 398 emails were sent. For those that did not have a listed email, a letter similar to the email solicitation was drafted and sent by mail to the remaining 541 license holders. Of the 541 mail-out letters, seven were returned due to bad addresses. Both the email and letters contained a hyperlink to the web-based survey. Furthermore, both emails and letters were followed up with multiple reminders. The email reminders were sent on the following dates: April, 21, April, 29, 
May, 12, May 30, and June, 27 of 2011. The first letter was distributed on May 2, 2011 with a reminder going out two weeks later on the $16^{\text {th }}$ of May. A final reminder was sent two weeks later on the $30^{\text {th }}$ of May.

Two versions of the survey were created in English and in Spanish to accommodate a number of fishers in the Florida Keys who only speak Spanish, as per the Florida Keys Commercial Fishermen's Association ( FKCFA) recommendation. The software program Qualtrics ${ }^{\circledR}$ provides an easy to use side by side translation tool. Both emails and letters, with the subsequent reminders contained both English and Spanish text.

In addition to emails and letters sent to all fishers, several trips were made to hand out hard copies of surveys in person. The chosen spot to hand out surveys were the various fish-houses in the Florida Keys. At the fish-houses, I was also able to talk with several fish-house owners. In these meetings I described the objectives of the survey and most of the owners were willing to take the surveys and distribute them to the fishers belonging to the fish-house. However, this method proved ineffective as only a few surveys were returned even though they were given pre-addressed envelopes with paid postage.

Collecting data from fishers in the Florida Keys proved more difficult than perceived. There was constant opposition from a variety of fishers. I was told by a number of sources that this was a challenge. During the data collection period, I received several calls and emails in which fishers expressed a very confrontational attitude about the survey. I believe that the reason for the confrontational attitudes of fishers was mainly because of the lack of information on fishers' behalf about the purpose of the study. 
Those who contacted me were under the impression that I was a manager of their particular fishery. Furthermore, fishers had a preconceived notion, for the most part, that I was in favor of dedicated access privileges. When I explained my position and the objectives of the study I was able to gather useful information from fishers. I was able to gain key insights regarding fisher perceptions on the various sections of the survey. Several times fishers would tell me that they would not participate in the study and then after our conversation, they would complete the survey. I felt that a large reason for a relatively small number of completed surveys was because of the fishers' opposition to many forms of management, more specifically to the dedicated access privileges.

Sixty-four surveys were completed. A total of 941 surveys were distributed. The response rate was $6.8 \%$. The email portion of the study had a response rate of $14.5 \%$ and the letters had a response rate of just over $1 \%$.

\section{CHAPTER 4}

\section{RESULTS AND DATA ANALYSIS}

\subsection{Description of the Sampled Florida Keys Commercial Fishing Fleet}

There are four sections in the survey. The first and last section of the survey instrument focuses on operation characteristics and social demographics. The other two sections ask for specific perceptions on various management frameworks. My study focuses on empirically investigating which of these operational characteristics and social demographics prefer specific management frameworks. On the basis of the hypothesis listed in chapter 2, the size of the operation was a key part of this study. Variables used to 
reflect the size of operation included the horsepower of the vessel, size of the crew, and vessel length. Variables that reflected the amount of effort that being used to fish, such as the number of trips per week were also included. Table 2 shows the complete list of variables used including a description of the variable. The number of observations, the minimum and maximum value, the mean, and the standard deviation corresponding to each variable are listed (Table 2).

Table 2. Definitions and descriptions of Variables used

\begin{tabular}{|c|c|c|c|c|}
\hline Variable & Variable description & $\mathbf{N}$ & Minimum & Maximum \\
\hline HP & Horse power of vessel & 72 & 10 & 1640 \\
\hline Crew & Number of crew present & 64 & 0 & 4 \\
\hline Crewchange & $\begin{array}{l}\text { Change in crew since creation of FKNMS (1- } \\
\text { increased, } 2 \text {-same, } 3 \text {-decreased) }\end{array}$ & 74 & 1 & 3 \\
\hline Vessel_length & Vessel length (in feet) & 64 & 14 & 53 \\
\hline Trips & Trips per week & 61 & 0 & 7 \\
\hline Tripchange & $\begin{array}{l}\text { Changes in trips per week since creation of } \\
\text { FKNMS (1-increased significantly, 2-increased, } \\
\text { 3-stayed the same, 4-decreased, 5- decreased } \\
\text { significantly) }\end{array}$ & 65 & 1 & 5 \\
\hline Fulltime & Full or part time fisher (1-Fulltime, 2-Parttime) & 65 & 1 & 2 \\
\hline Parents & Were one or both parents fishers (1-yes, 2-no) & 65 & 1 & 2 \\
\hline Children & Do fishers see children in business (1-yes, 2-no) & 64 & 1 & 2 \\
\hline Ownership & $\begin{array}{l}\text { Do fishers own vessel they work on (1-yes, 2- } \\
\text { no) }\end{array}$ & 64 & 1 & 2 \\
\hline Vessels_owned & How many vessels does the fisher own & 59 & 1 & 3 \\
\hline Experience & $\begin{array}{l}\text { How long have fishers been in commercial } \\
\text { fishing (years) }\end{array}$ & 64 & 4 & 60 \\
\hline Experience_Keys & $\begin{array}{l}\text { How long have fishers been commercial fishers } \\
\text { in Keys (years) }\end{array}$ & 64 & 2 & 60 \\
\hline Age & Fisher age & 64 & 26 & 81 \\
\hline Household & how many people reside in the household & 64 & 1 & 4 \\
\hline Member & $\begin{array}{l}\text { Does the fisher belong to any associations or } \\
\text { clubs (1-yes, 2-no) }\end{array}$ & 65 & 1 & 2 \\
\hline
\end{tabular}


As listed in Table 2, the maximum value of horsepower on board was $1640 \mathrm{hp}$. This was well above the mean of 380.35 . The number of crew present for the industry also indicated a relatively small operation for the industry with the maximum crew present being four. Most respondents indicated that there has been little change in the amount of crew present since the creation of the Florida Key National Marine Sanctuary. Mean vessel length was less than thirty feet. Average trips were 3.56 trips per week.

The majority of those surveyed indicated that they were fulltime fishers. Most respondents reported that they were first generation fishers and do not believe that their children will be in the industry. The average experience of commercial fishers is 27.98 years. Fisher age ranged from 26 to 81 with a mean of 55.84. Respondents indicated that the average number of people in their household was 2.19. When asked if fishers belonged to any regional, local, or national association of organization, half indicated that they did belong to at least one such group. The largest percentage of fishers based on gear type was hook and line (Table 3). Fishers were able to log multiple gear types due to the number of fishers who use multiple gear types. According to Figure 2, twenty percent of fishers reported making over $\$ 100,000$. The majority of fishers make between $\$ 40,000$ and $\$ 60,000$.

Table 3. Frequency of gear type

\begin{tabular}{|c|c|c|c|c|c|c|c|c|}
\hline \multicolumn{9}{|c|}{ Frequency of Gear Type } \\
\hline Gear Type & $\begin{array}{c}\text { Trap/Ca } \\
\text { ge }\end{array}$ & $\begin{array}{c}\text { Hook } \\
\text { and } \\
\text { Line }\end{array}$ & $\begin{array}{c}\text { Lon } \\
\mathrm{g} \\
\text { Line }\end{array}$ & $\begin{array}{c}\text { Midwate } \\
\text { r Trawl }\end{array}$ & $\begin{array}{c}\text { Botto } \\
\text { m } \\
\text { Trawl }\end{array}$ & Troll & $\begin{array}{c}\text { Spearfis } \\
\mathrm{h}\end{array}$ & $\begin{array}{c}\text { Lobste } \\
r \\
\text { Diving }\end{array}$ \\
\hline Valid & 24 & 48 & 2 & 0 & 0 & 6 & 12 & 22 \\
\hline $\mathbf{N}$ & 74 & 74 & 74 & 74 & 74 & 74 & 74 & 74 \\
\hline Percentage & 32.43 & 64.86 & 2.7 & 0 & 0 & 8.1 & 16.21 & 29.72 \\
\hline
\end{tabular}


Figure 2. Percentage of Fisher Income

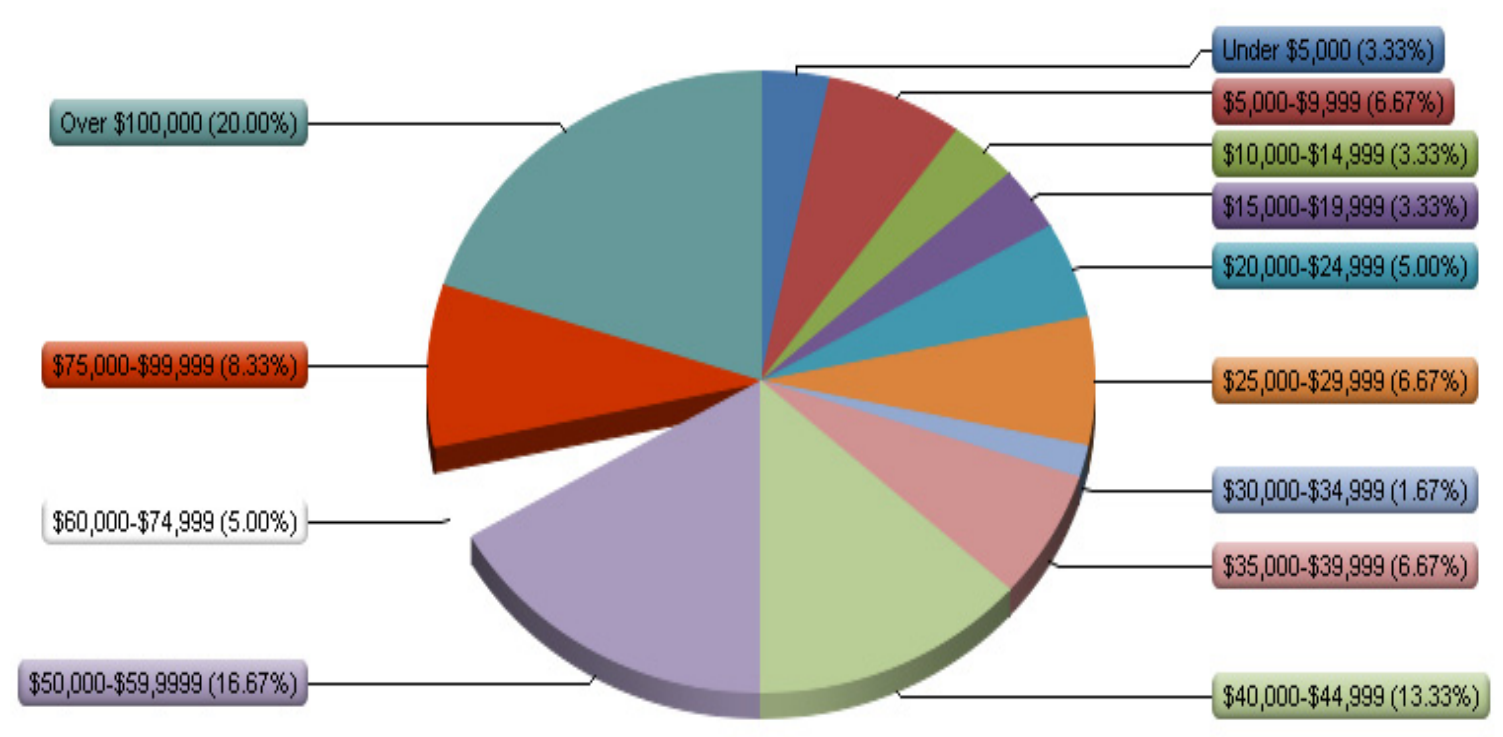

Fishers were asked to give their opinion on current management practices. These included questions on if fishers believed that the no take marine protected areas in the FKNMS were effective as fishery management tools. Table 3 shows the responses to these questions. Fisher responses to questions concerning alternative management practices were also included. 
Table 4. Definitions and Descriptive Statistics of Variables used (continued)

\begin{tabular}{|c|c|c|c|c|c|c|}
\hline Variable & Variable description & $\mathbf{N}$ & Min & Max & Mean & SD \\
\hline Resarch_worked & $\begin{array}{l}\text { Do fishers feel that the Research Only areas are viable to } \\
\text { FKNMS strategy (1-yes, 2-neutral, 3-no) }\end{array}$ & 72 & 1 & 3 & 2.53 & 1.768 \\
\hline ER_worked & $\begin{array}{l}\text { Do fishers feel that the Ecological Reserves are beneficial in } \\
\text { increasing fish stock (1-yes, 2-neutral, 3-no) }\end{array}$ & 73 & 1 & 3 & 2.03 & .666 \\
\hline Zones_business & $\begin{array}{l}\text { How have these zones affected business (1-much worse, 2- } \\
\text { worse, } 3 \text {-no affect, 4-better, 5- much better) }\end{array}$ & 73 & 1 & 4 & 2.71 & .808 \\
\hline Stakeholders & $\begin{array}{l}\text { Were all stakeholder given equal treatment in designing reserves } \\
\text { (1-yes, 2-no) }\end{array}$ & 69 & 1 & 2 & 1.64 & .484 \\
\hline Fish Stocks & $\begin{array}{l}\text { The FKNMS is a tool in maintaining fish stocks (1-strongly } \\
\text { disagree, 2-disagree, 3-neutral, 4-agree, 5-strongly agree }\end{array}$ & 68 & 1 & 5 & 2.29 & 1.185 \\
\hline Profession & $\begin{array}{l}\text { Likelihood of fisher changing his profession to a non-fisher (1- } \\
\text { very unlikely, 2-unlikely, 3-neutral, 4-likely, 5-very likely) }\end{array}$ & 71 & 1 & 5 & 2.70 & 1.408 \\
\hline IFQ & $\begin{array}{l}\text { Would non-transferable DAPs (IFQs) be beneficial to the } \\
\text { industry (1-yes, 2-not sure, 3-no) }\end{array}$ & 72 & 1 & 3 & 2.53 & 1.768 \\
\hline ITQ & $\begin{array}{l}\text { Would transferable DAPs (ITQs) be beneficial to the industry (1- } \\
\text { yes, 2-not sure, 3-no) }\end{array}$ & 73 & 1 & 3 & 2.03 & .666 \\
\hline Extend_IFQ & $\begin{array}{l}\text { Would non-transferable DAPs (IFQs) extend the fishing season } \\
\text { (1-yes, 2-not sure, 3-no) }\end{array}$ & 73 & 1 & 4 & 2.71 & .808 \\
\hline Extend_ITQ & $\begin{array}{l}\text { Would transferable DAPs (ITQs) extend the fishing season (1- } \\
\text { yes, 2-not sure, 3-no) }\end{array}$ & 69 & 1 & 2 & 1.64 & .484 \\
\hline IFQ_Better & $\begin{array}{l}\text { Would non-transferable DAPs (IFQs) be better than the current } \\
\text { framework (1-yes, 2-not sure, 3-no) }\end{array}$ & 68 & 1 & 5 & 2.29 & 1.185 \\
\hline ITQ_Better & $\begin{array}{l}\text { Would transferable DAPs (ITQs) be better than the current } \\
\text { framework (1-yes, 2-not sure, 3-no) }\end{array}$ & 71 & 1 & 5 & 2.70 & 1.408 \\
\hline $\begin{array}{l}\text { Specific_Operation } \\
\text { IFQ }\end{array}$ & $\begin{array}{l}\text { Would non-transferable DAPs (IFQs) benefit certain operations } \\
\text { over others (1-yes, 2-not sure, 3-no) }\end{array}$ & 60 & 1 & 3 & 1.43 & .745 \\
\hline $\begin{array}{l}\text { Specific_Operation } \\
\text { ITQ }\end{array}$ & $\begin{array}{l}\text { Would transferable DAPs (ITQs) benefit certain operations over } \\
\text { others (1-yes, 2-not sure, 3-no) }\end{array}$ & 61 & 1 & 3 & 1.41 & .716 \\
\hline
\end{tabular}




\begin{tabular}{|c|l|c|c|c|c|c|}
\hline ITQ_IHQ & $\begin{array}{l}\text { Would a combination of ITQs and IHQs be more cost effective } \\
\text { than a strictly MPA framework (1-yes, 2-not sure, 3-no) }\end{array}$ & 42 & 1 & 3 & 2.52 & .833 \\
\hline Buffer & $\begin{array}{l}\text { Would you support the creation of buffer zones around areas of } \\
\text { no-take (1-yes, 2-neutral, 3-no) }\end{array}$ & 58 & 1 & 3 & 2.67 & .735 \\
\hline
\end{tabular}


Earlier, it was stated that the FKNMS is divided into several distinct zones. Each one is designed to serve a specific purpose. Since all no take areas are free from harvest, they can act as areas of replenishment into surrounding areas (McClanahan 2001). Respondents were asked about how they believe each of these zones has performed according to its original purpose. Fishers were then asked if the FKNMS as a whole is beneficial to maintaining and replenishing fish stocks.

When asked if the "Research Only" areas were a viable part of the FKNMS, fishers stated that they did not believe that it was. Fishers were neutral when asked about the "Ecological Reserves." When asked how the combined zones had affected business operations, fishers responded that there has been little effect. Fishers responded to the statement, "the FKNMS is an important tool in maintaining and increasing fish habitats", with a mean of 2.29 (1-Strongly disagree, 5-Strongly agree). During the designing process, various stakeholder groups were included. Fishers were asked if all stakeholders were given equal. A mean of 1.64 was reported.

The next section included questions concerning alternative management practices. Included among these were the various forms of dedicated access privileges. The questions about dedicated access privileges were centered around the unique aspects of each of the types including perceived benefits to the industry, extension of the fishing season, and if dedicated access privileges (DAP) would be better than the current frame work. Fishers were also asked if DAPs would benefit certain operations over others.

Fishers do not believe that IFQs (i.e., non-transferable DAPs) would be beneficial to the industry as a whole. When asked the same question for ITQs (transferable DAPs), fishers were not sure if ITQs would be beneficial to the industry. When asked if IFQs and 
ITQs would extend the fishing season, fishers responded with diverse opinions. They believed that IFQs would not extend the season however, ITQs would extend the fishing season. Fishers responded with clear objections to the questions that ask if IFQs and ITQs would be better than the current framework. The last question concerning DAPs focused on if fishers believed that DAPs would benefit certain operations over others. The response to both types of DAPs was yes. The prevailing belief is that certain operations (i.e. small vs. large) would benefit more than others with the implementation of both non-transferable and transferable DAPs.

\subsection{Fisher Perceptions of FKNMS as a Fishery Management Tool}

Fishers in the Florida Keys stated that they believed no-take areas in the keys were either not working according to the stated purpose or were neutral in their response (see Table 4). To determine how commercial fishers believe the FKNMS has affected specific aspects of their business, questions were asked covering three specific areas of interest. The areas of interest are the current perception of the effects of the FKNMS on the industry. The second asks fishers to give a response if the FKNMS had not been created. The third area asks fishers to imagine a scenario where the FKNMS were to lose all protection. The question asks to rate the status of the industry ten years from the loss of protection. For each of the three areas, seven variables were used to measure the condition of the industry. These included the condition of the species targeted, the overall catch, the competition among fishers, the size of the catch, the cost of business, the price of catch, and the demand for the product. 
Table 5. Fisher Perception on Effects of Florida Keys National Marine Sanctuary on Fishery

\begin{tabular}{|c|c|c|c|c|c|c|}
\hline Variable & Variable description & $\mathbf{N}$ & Minimum & Maximum & Mean & $\begin{array}{c}\text { Std. } \\
\text { Deviation }\end{array}$ \\
\hline Eff-species & $\begin{array}{l}\text { Effect of the FKNMS on species normally } \\
\text { targeted }\end{array}$ & 66 & 1 & 4 & 2.79 & .691 \\
\hline Eff-catch & Effect of the FKNMS on overall catch & 66 & 1 & 4 & 2.67 & .687 \\
\hline $\begin{array}{c}\text { Eff- } \\
\text { competition }\end{array}$ & $\begin{array}{l}\text { Effect of the FKNMS on competition among } \\
\text { fishers }\end{array}$ & 65 & 1 & 4 & 2.35 & .818 \\
\hline Eff-size & Effect of the FKNMS on size of catch & 66 & 1 & 4 & 2.68 & .788 \\
\hline Eff-cost & Effect of the FKNMS on cost of business & 65 & 1 & 5 & 2.23 & .932 \\
\hline Eff-price & Effect of the FKNMS on price of catch & 64 & 1 & 5 & 2.75 & .777 \\
\hline Eff-demand & Effect of the FKNMS on demand for product & 64 & 1 & 5 & 2.86 & .687 \\
\hline
\end{tabular}

Note: Respondents were asked to provide their opinion on a 1-5 scale. 1-extremely negative, 2-negative, 3-no affect, 4positive, 5-extremely positive 
Table 6. Fisher Perception on Current Status if FKNMS had not been created

\begin{tabular}{|c|c|c|c|c|c|c|}
\hline Variable & Variable description & $\mathbf{N}$ & $\begin{array}{c}\text { Mi } \\
\text { n }\end{array}$ & $\begin{array}{c}\text { Ma } \\
\mathbf{x}\end{array}$ & $\begin{array}{c}\text { Mea } \\
\text { n }\end{array}$ & SD \\
\hline NC-S & $\begin{array}{l}\text { If the FKNMS had not been created what would be the current condition of } \\
\text { the species normally targeted }\end{array}$ & 67 & 1 & 5 & 3.10 & $\begin{array}{c}.65 \\
4\end{array}$ \\
\hline NC-catch & $\begin{array}{l}\text { If the FKNMS had not been created what would be the current condition be } \\
\text { of the overall catch }\end{array}$ & 66 & 2 & 5 & 3.18 & $\begin{array}{c}.63 \\
0\end{array}$ \\
\hline $\begin{array}{c}\text { NC- } \\
\text { competition }\end{array}$ & $\begin{array}{l}\text { If the FKNMS had not been created what would be the current condition be } \\
\text { of the competition among fishers }\end{array}$ & 66 & 1 & 5 & 3.24 & $\begin{array}{c}.72 \\
5\end{array}$ \\
\hline NC-size & $\begin{array}{l}\text { If the FKNMS had not been created what would be the current condition of } \\
\text { the size of catch }\end{array}$ & 64 & 1 & 5 & 3.09 & $\begin{array}{c}.68 \\
4\end{array}$ \\
\hline $\mathrm{NC}-\mathrm{c}$ & $\begin{array}{l}\text { If the FKNMS had not been created what would be the current condition be } \\
\text { of the cost of business }\end{array}$ & 65 & 1 & 5 & 3.25 & $\begin{array}{c}.75 \\
1\end{array}$ \\
\hline NC-price & $\begin{array}{l}\text { If the FKNMS had not been created what would be the current condition be } \\
\text { of the price of catch }\end{array}$ & 66 & 1 & 5 & 3.12 & $\begin{array}{c}.66 \\
8\end{array}$ \\
\hline NC-demand & $\begin{array}{l}\text { If the FKNMS had not been created what would be the current condition be } \\
\text { of the demand for product }\end{array}$ & 66 & 2 & 5 & 3.20 & $\begin{array}{c}.56 \\
1\end{array}$ \\
\hline
\end{tabular}

Note: Respondents were asked to provide their opinion on a 1-5 scale. 1-extremely negative, 2-negative, 3-no affect, 4positive, 5-extremely positive 
Table 7. Fisher Perceptions on Future Fisheries if the FKNMS were Cease to Exist

\begin{tabular}{|c|c|c|c|c|c|c|}
\hline Variable & Variable description & $\mathbf{N}$ & Min & Max & Mean & SD \\
\hline Future_species & $\begin{array}{l}\text { If the FKNMS were cease to exist what would be the condition of the } \\
\text { species normally targeted in } 10 \text { years }\end{array}$ & 68 & 1 & 5 & 2.91 & .842 \\
\hline Future_catch & $\begin{array}{l}\text { If the FKNMS were cease to exist what would be the condition of the } \\
\text { overall catch in } 10 \text { years }\end{array}$ & 68 & 1 & 5 & 2.94 & .862 \\
\hline Future_competition & $\begin{array}{l}\text { If the FKNMS were cease to exist what would be the condition of the } \\
\text { competition among fishers in } 10 \text { years }\end{array}$ & 68 & 1 & 5 & 2.94 & .826 \\
\hline Future_size & $\begin{array}{l}\text { If the FKNMS were cease to exist what would be the condition of the } \\
\text { size of catch in } 10 \text { years }\end{array}$ & 68 & 1 & 5 & 2.97 & .846 \\
\hline Future_cost & $\begin{array}{l}\text { If the FKNMS were cease to exist what would be the condition of the } \\
\text { cost of business in } 10 \text { years }\end{array}$ & 68 & 1 & 5 & 3.15 & .778 \\
\hline Future_price & $\begin{array}{l}\text { If the FKNMS were cease to exist what would be the condition of the } \\
\text { price of catch be in } 10 \text { years }\end{array}$ & 68 & 1 & 5 & 3.10 & .775 \\
\hline Future_demand & $\begin{array}{l}\text { If the FKNMS were cease to exist what would the condition be on } \\
\text { demand for product be in } 10 \text { years }\end{array}$ & 68 & 1 & 5 & 3.16 & .745 \\
\hline
\end{tabular}

Note: Respondents were asked to provide their opinion on a 1-5 scale. 1-extremely negative, 2-negative, 3-no affect, 4positive, 5 -extremely positive 
The first area of focus was how fishers believe the FKNMS had affected each of the seven variables. Table 5 shows the results of the area studied. Fishers were given five choices to choose from for each of the seven variables for each area. The choices range from 1 being extremely negative to 5 being extremely positive. Having no affect was 3 . The closer the fisher responses were to 3, the more they believe the FKNMS has had no effect on that aspect of their fishery. Fishers were fairly consistent across all seven variables for the first area. All means were between negative (2) and no affect (3) with five of the seven variables having means above 2.5. The results show that the creation of the FKNMS has had little effect on commercial fishery as perceived by the fishers. The results also concur with Shivlani (2006) that show fishers had been relatively unaffected ten years after creation of the Florida Keys national Marine Sanctuary. Figure 3 shows the percentage of fishers who reported the extent that the FKNMS has affected each variable. Five of the seven variables were rated as the FKNMS having no effect. Only the competition among fishers and the cost of business were rated as being negatively affected when the FKNMS was created. Furthermore, the cost of business had the lowest mean of any of the seven variables. One quarter of those responding to the cost of business reported that the FKNMS had affected it in an extremely negatively way. This percentage was the highest among any of the other seven variables. When speaking with fishermen about the creation of the FKNMS, they frequently cited having to use more fuel to get to fishing grounds. 
Figure 3. Commercial fishers opinion on how they feel the creation of the FKNMS has affected the condition of the species normally targeted, the overall catch, the competition among fishers, size of catch, cost of business, price of catch, and the demand for product.

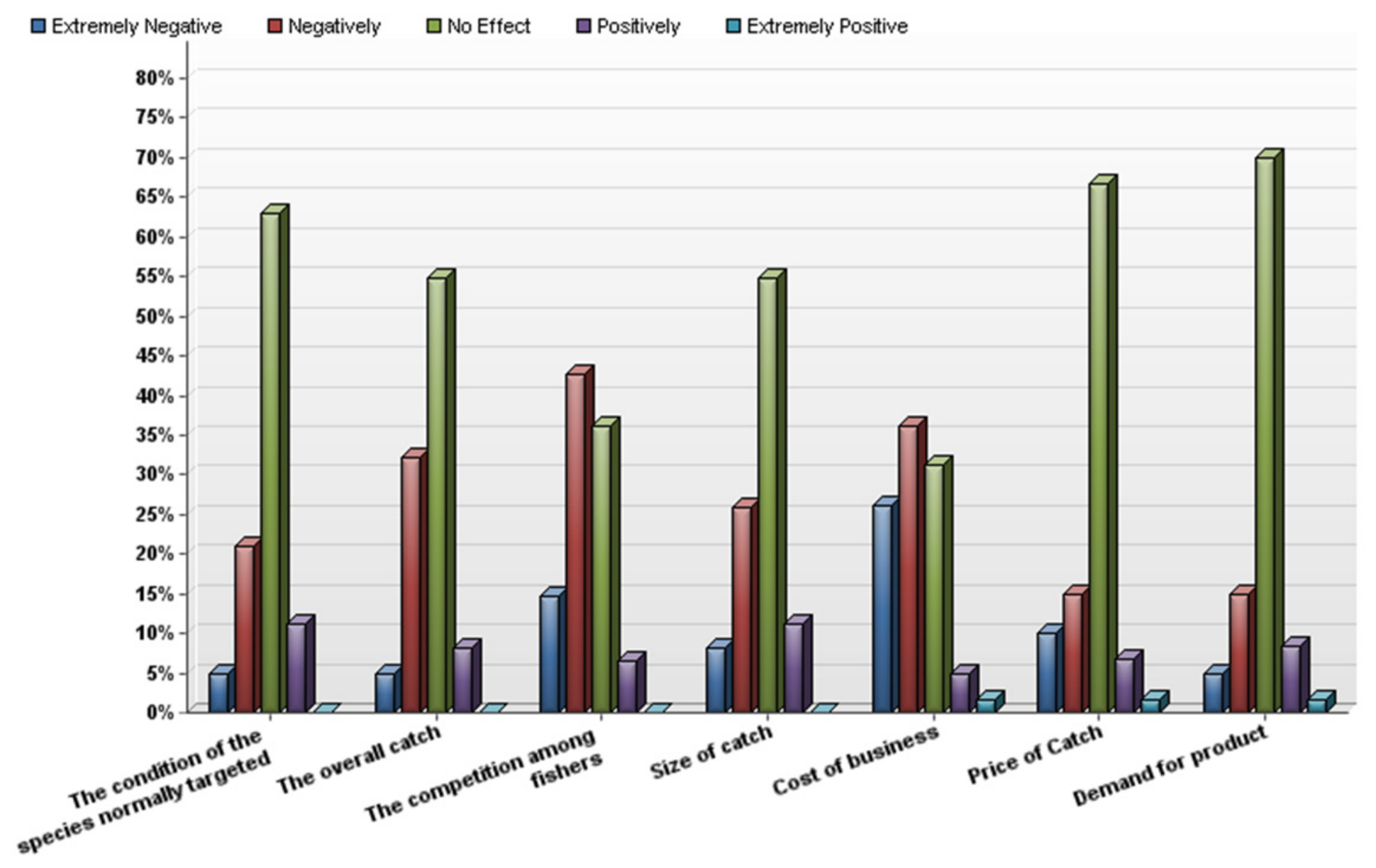


Figure 4. Commercial fishers opinion on how they feel the condition of the species normally targeted, the overall catch, the competition among fishers, size of catch, cost of business, price of catch, and the demand for product had the FKNMS not been created.

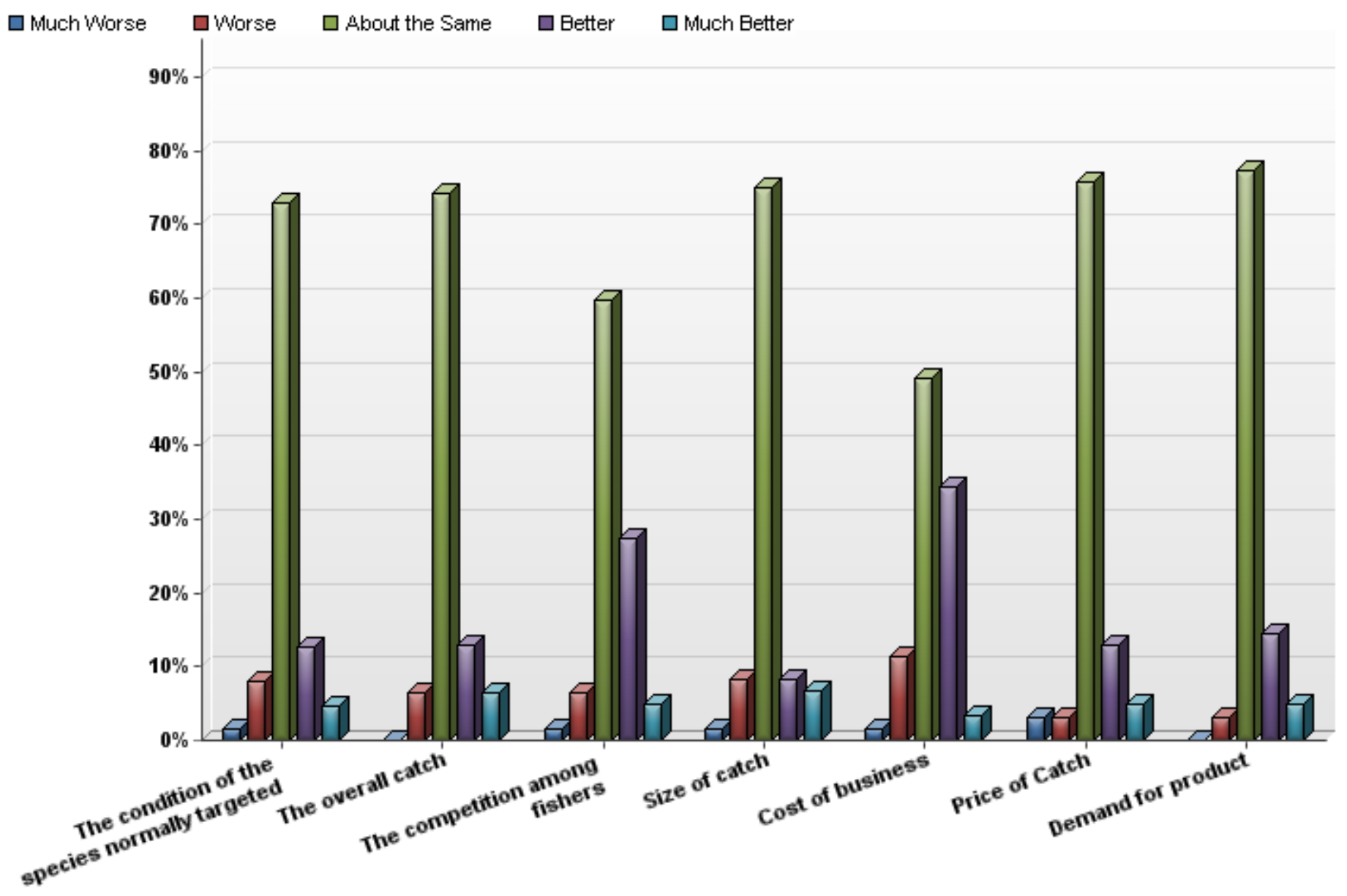


Table 6 deals with how fishers believe the seven variables (the condition of the species normally targeted, the overall catch, competition among fishers, size of the catch, the cost of business, the price of the catch, and the demand for product) would be if the FKNMS had never been created. Similar to how fishers believe the FKNMS had affected the seven variables, most fishers were neutral in their responses stating that they believe the all variables would be about the same as they are today. Similar still to the previous area of focus, all means were close to three, indicating a neutral stance (Table 5). However, a noticeable difference between how the FKNMS had affected fishers and how fishers would be impacted had the FKNMS not been created is in the fact that the means shift closer to a value larger than neutral, showing that many fishers believe that the condition of the variables would be in a better condition than they presently are. Figure 4 shows the percentage of fishers that believe the condition of each of the seven variables to be in if the FKNMS had not been created. All seven of the variables indicated that fishers believe that the condition of each of the variables would be in the same condition had the FKNMS not been created. In contrast to the first area studied, the "cost of business" and "competition" variables both went from being in the less than neutral to a more than neutral position. The switch indicates a position among fishers that, for many, the competition would be less and the cost of business would decrease if the FKNMS would not have been created.

Table 7 shows the results of the third area of inquiry which asks fishers what they believe would be the condition of the seven variables in ten years if all protection of the FKNMS were to cease. Much like the other two areas studied, fishers took a neutral stance. Fishers believe that there would be little if any change to condition of the species targeted, 
the overall catch, the completion among the fishers, and the size of the catch. Furthermore, fishers believe there would be no change in the cost of business, the price of catch, or in the demand for product as a result of the FKNMS ceasing to exist. Figure 5 shows the percentage of fishers that responded to the future condition of the fishery without the Florida Keys National Marine Sanctuary. 
Figure 5. Shows how commercial fishers feel the condition of species normally targeted, the overall catch, the competition among fishers, size of catch, cost of business, price of catch, and the demand for product would be in 10 years from now, if the FKNMS were to lose all protection.

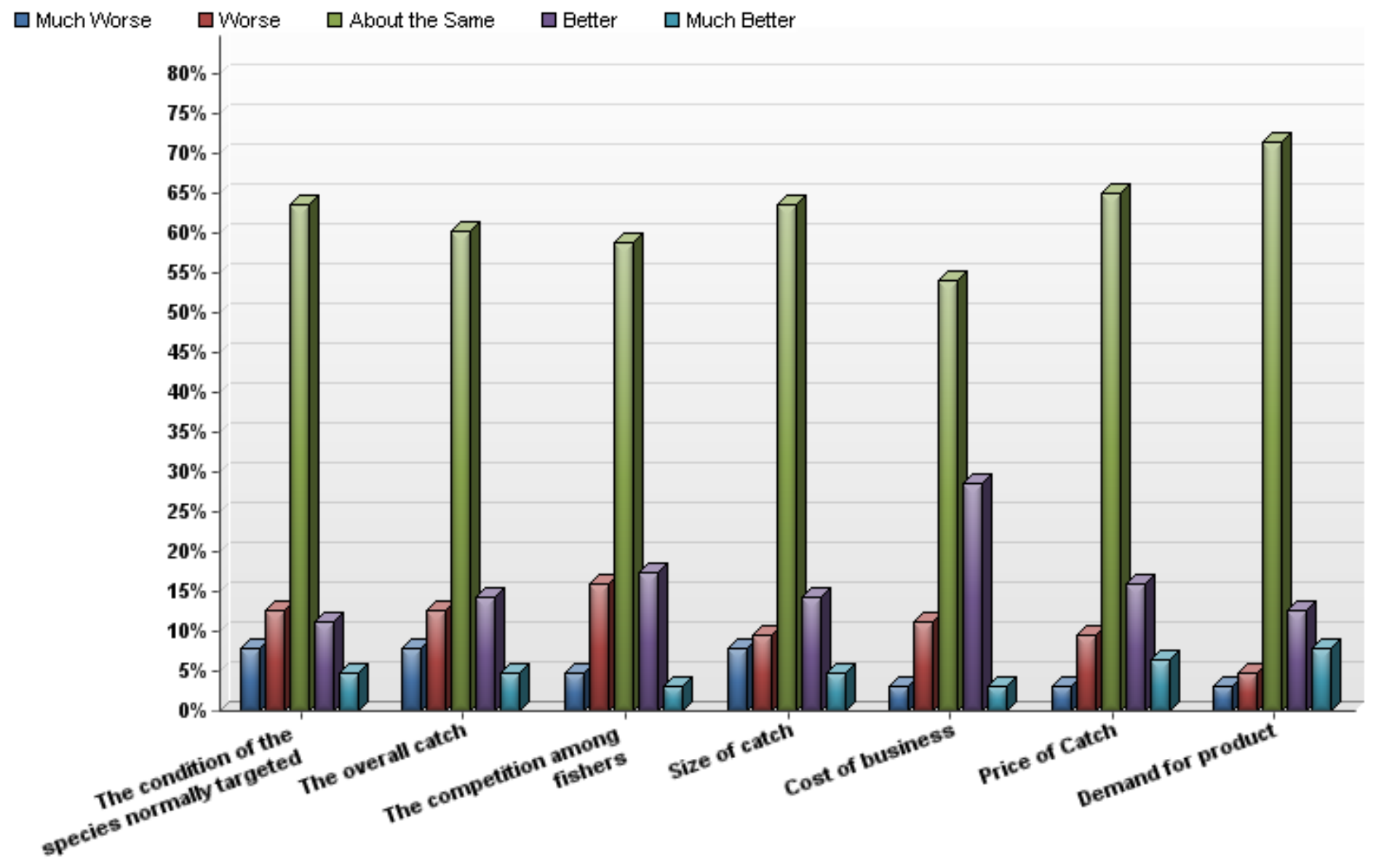


One aspect of this research is to study change in fisher perceptions over time. By looking at how fishers feel about certain management practices over a period of time, including marine protected areas, managers can better adjust management frameworks to adapt to changing perceptions. Suman et al. (1999) explored the initial perceptions of the FKNMS among various stakeholders, including commercial fishers. Shivlani (2006) showed how perceptions had changed over a ten year period, since the FKNMS was created. As stated earlier, commercial fisher attitudes went from a strong against stance, to a more neutral stance. However a majority of commercial fishers still did not support the Florida Keys National Marine Sanctuary. Figure 6 shows the change in support of sampled fishers from their initial support to their current support. The percentage of those that oppose the FKNMS decreased from $52.94 \%$ to 47.76 percent. The percentage of those that support the FKNMS rose by just under two percent. The percentage of those that are neutral towards the FKNMS establishment has increased.

Pita (2010) shows that how fishers that are involved in the creation and drafting of management plans affects how they perceive the implemented framework. In my study, fishers were asked to give their opinions on the stakeholders affected by the creation of the Florida Keys National Marine Sanctuary. I asked fishers to respond to a statement that suggest if all stakeholders were given equal treatment when the FKNMS was being proposed and drafted. A large majority of fishers responded by stating that stakeholders were not given equal treatment during the draft process. Only $35 \%$ of those surveyed believe that stakeholders were given equal treatment in the draft process compared to $65 \%$ who disagreed (Figure 7 ). 
Figure 6. Change in Support of Commercial Fishers toward the Florida Keys National Marine Sanctuary
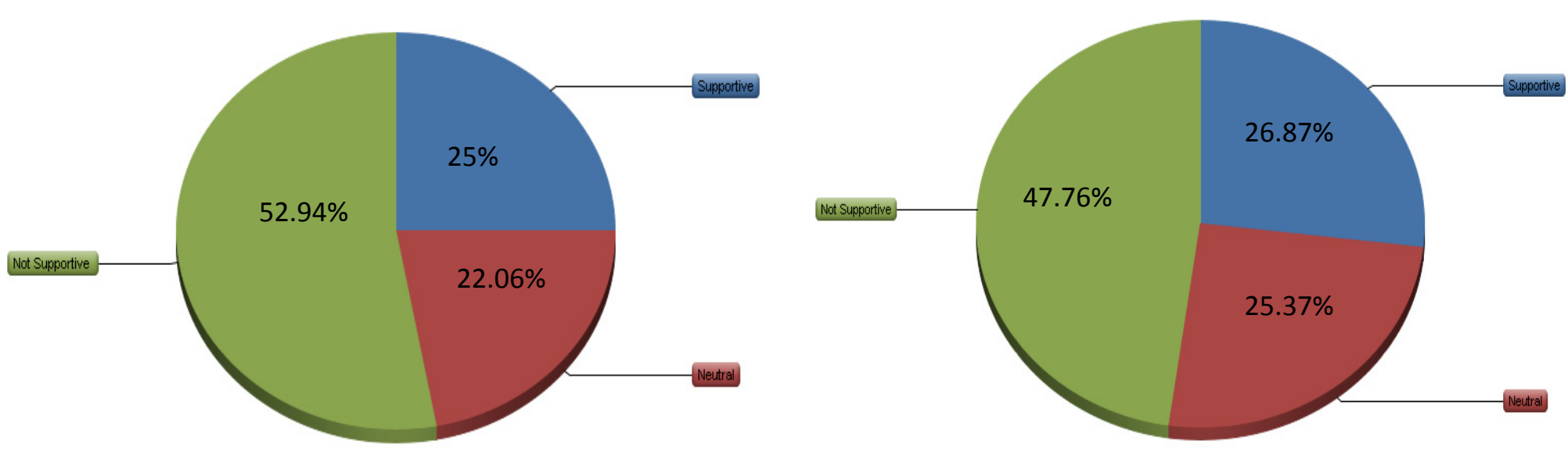

Figure 6a. Initial Support

Figure 6b. Support Now 
After fishers were asked about equal treatment of stakeholders, the respondents were asked to rank which stakeholder benefitted the most from the FKNMS creation. Fishers were given a list of six stakeholders and asked to rank in order from most benefitted to least benefitted. The six stakeholders were dive boat operators, recreational fishermen, commercial fishermen, scientists, environmental groups, and recreational diver/snorkelers. Figure 8 shows the results of the stakeholder ranking question. The stakeholder who the fishers believe has been benefitted the most is environmental groups. Following environmental groups are scientists, dive boat operators, and recreational divers/snorkelers respectively. Fishermen were perceived as the stakeholders who have benefitted the least. Recreational fishers were ranked fifth and commercial fishers ranked sixth. Respondents strongly felt that commercial fishers benefitted the least as the commercial fishermen stakeholder group (Figure 8) received $83.87 \%$ of all last place rankings. When compared to the first place ranking of environmental groups, which received less than half of all benefitted the most votes (41.93\%), the higher percentage of votes show that commercial fishers were in agreement that they believe commercial fishers to have benefitted the least with the creation of the Florida Keys National Marine Sanctuary. Commercial fishers were also in agreement that recreational fishers also have benefitted little by the FKNMS creation responding with $64.51 \%$ of all fifth place votes.

The FKNMS is divided into several distinct zones. Fishers were asked to opine on how these zones have worked according to their original purpose. Fishers were also asked to give their opinion on these zones as potential fishery management tools. 
Figure 7. Fishers' opinion on if equal treatment was given to individual stakeholders

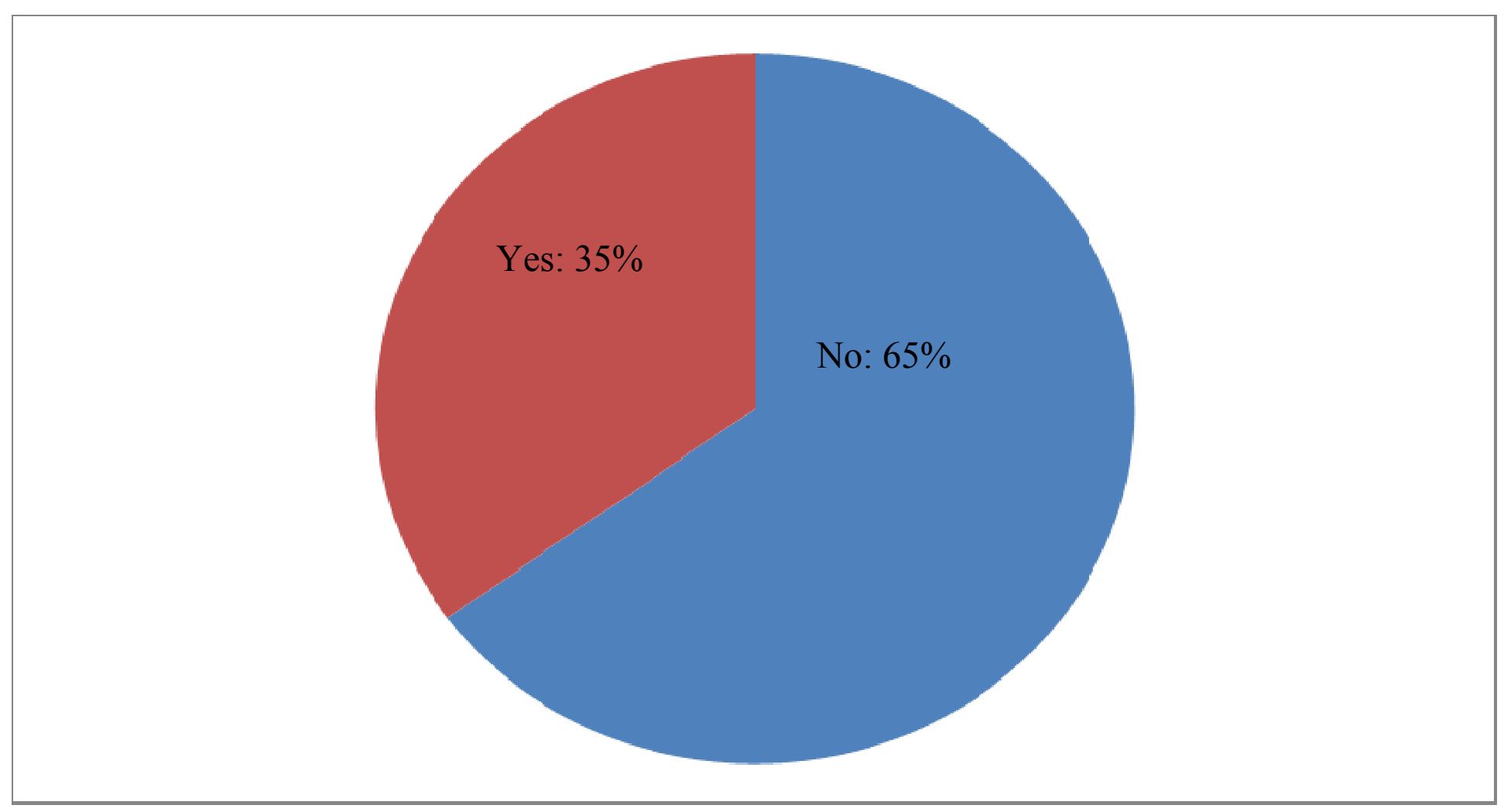


Figure 8. Fishers were asked to rank which stakeholders benefitted the most from the creation of the FKNMS

$\square 1$

$\square 2 \quad \square 3 \quad \square 4 \quad \square 5 \quad \square 6$

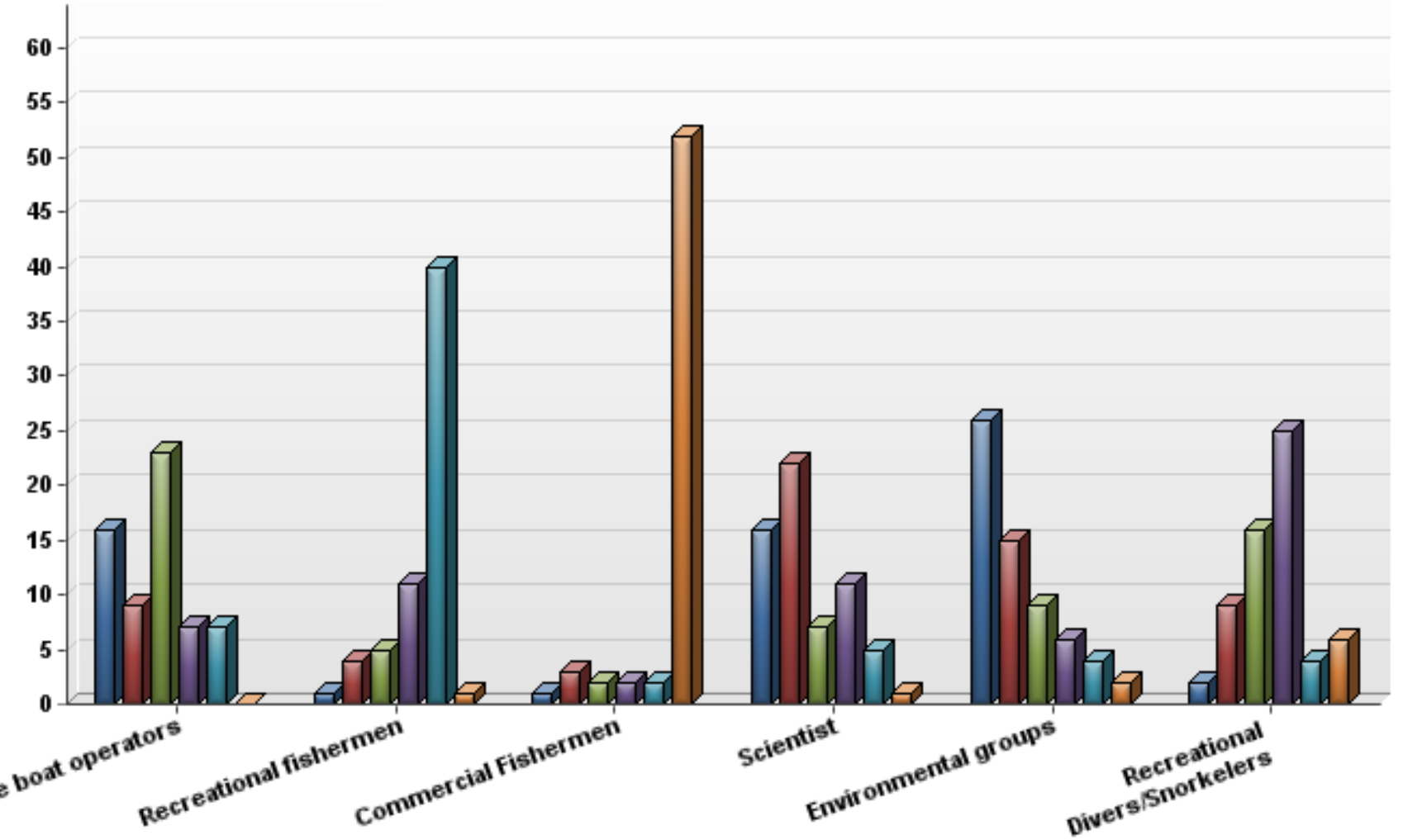


The three zones focused here are the sanctuary preservation areas (SPA), research only areas, and the ecological reserves (ER). Each of these areas is a no-take area. Respondents were given a brief description of each of the specific zones prior to the question. Table 4 shows the results for each of the three zones. Fishers were then asked to state whether or not they would support the creation of more of the three types of zones discussed. Fishers overwhelmingly responded that they would not support the creation of anymore no-take areas (Figure 9). For each of the three areas, SPAs, research only areas, and ecological reserves, fishers responded with no less than $67 \%$ of not favoring creation of more no take zones. Sanctuary preservation areas were the zone type least favored by commercial fishers for further creation ( $78.46 \%$ were not in favor for further creation). Furthermore, $7.6 \%$ were neutral toward further creation and $13.94 \%$ were in favor of further creation of sanctuary preservation areas. Research only areas were the next least favored for creation with $70.31 \%$ not in favor of further creation. Ecological reserves had a $67.18 \%$ response rate of not in favor of further creation.

The final area of inquiry concerning fishers and the FKNMS was whether or not fishers believed the FKNMS was a beneficial tool for managing fisheries (Figure 10). Most fishers either disagreed with the statement or strongly disagreed with the statement. The percentage of those that disagreed or strongly disagreed was 59\%. The largest percent response (35\%) was in the strongly disagree category. Nearly the same percent of fishers that disagreed with the statement (24\%), also agreed (22\%) that the FKNMS is an important tool for maintaining fisheries. Those that neither agree nor disagree were $17 \%$ while those that strongly agree were $2 \%$. 
Figure 9. The support of fishers for more no-take areas in the FKNMS

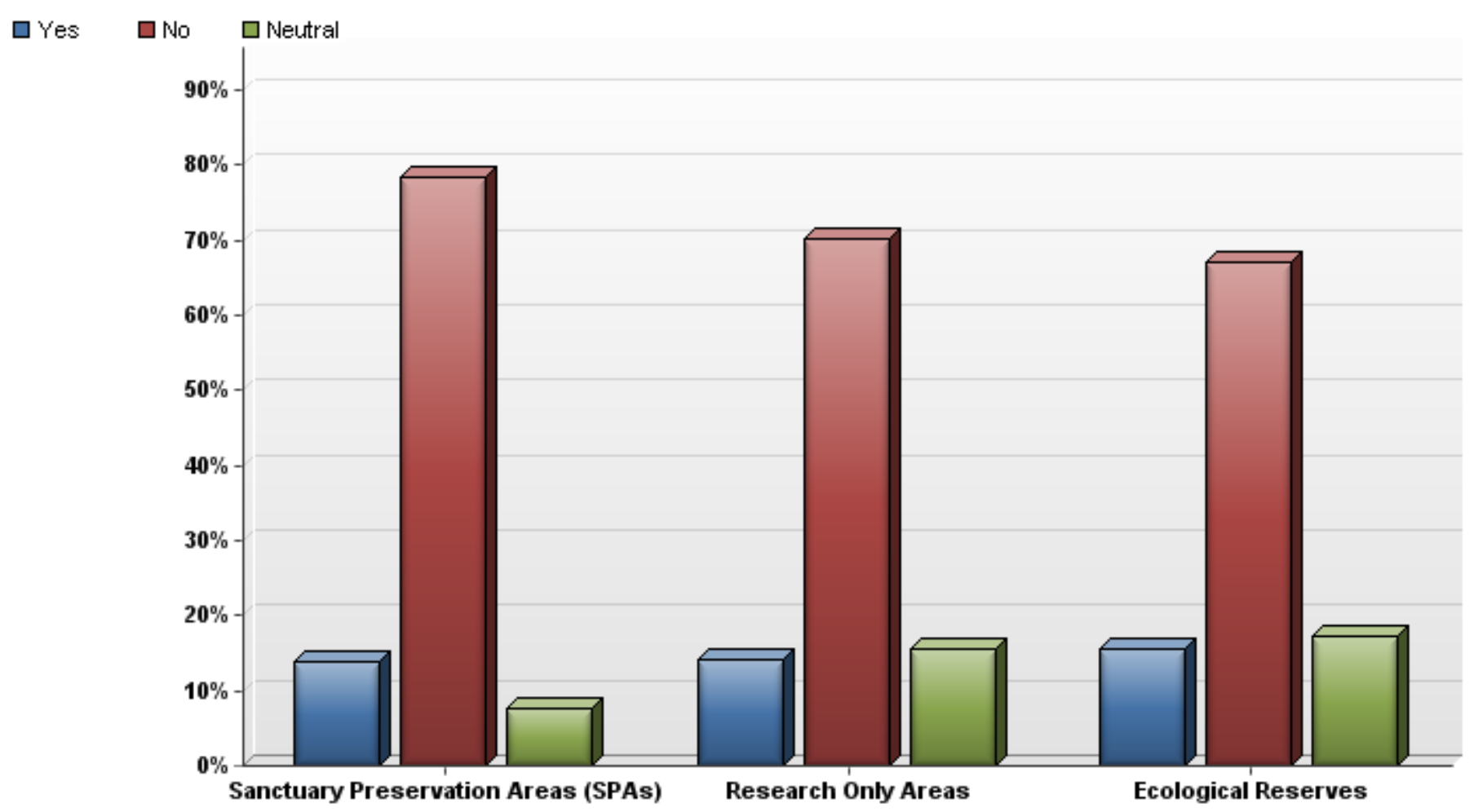


Figure 10. Fisher response when asked to respond to the statement, "the FKNMS has been a beneficial tool for managing fisheries"

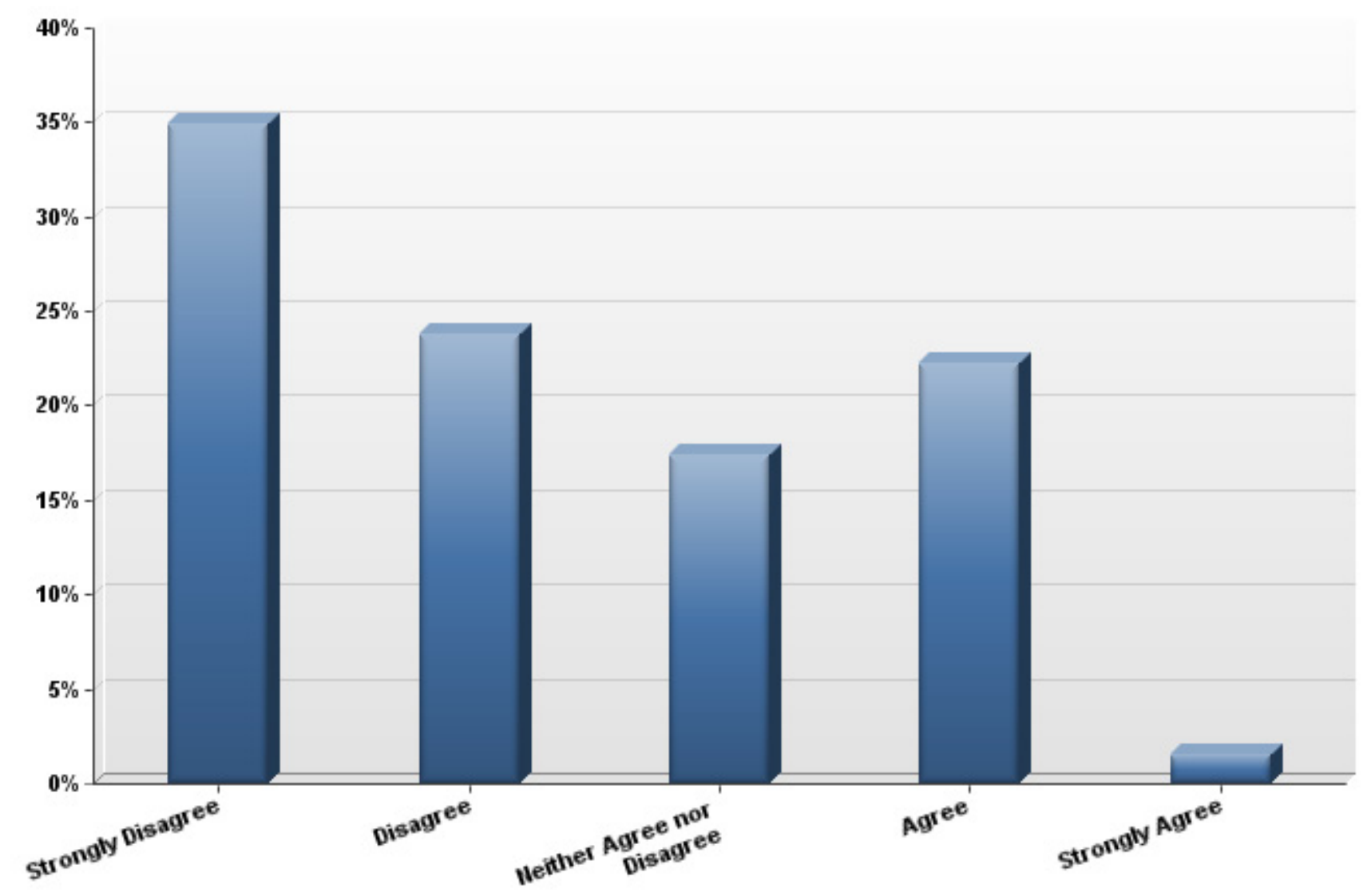




\subsection{Fisher perceptions of alternative management practices}

After fishers gave their opinions regarding the FKNMS as a fishery management tool, they were asked to give their opinion of various alternative management practices. More specifically, fishers were asked about dedicated access privileges and the possibility of using buffer zones around the no-take areas. To analyze fisher preference I used logistical regression models. Six models were estimated to test six dependent variables (IFQ, ITQ, Specific_operation_ifq, Speciffic_operation_itq, ITQ_IHQ, Buffer). Two different versions of the model for each dependent variable were estimated. One was a parsimonious model with a limited set of variables. The other is the extended model to check the robustness of findings with additional variables included. For each of the six dependent variables, 1 implies a yes response and 0 implies a no response (see Tables 2 and 4). When fishers were asked questions about their support for alternative management strategies, they were asked if they agreed, disagreed, or were neutral. To estimate which management frameworks were preferred, all neutral responses were dropped. The generic model is as follows:

$$
\text { Generic Model: } y_{\mathrm{i}}=\alpha+\beta_{1} \mathrm{X}_{1}+\beta_{2} \mathrm{X}_{2}+\beta_{3} \mathrm{X}_{3} \ldots \ldots \beta_{\mathrm{i}} \mathrm{X}_{\mathrm{i}}+\mathrm{U}_{\mathrm{i}}-1
$$

Where $\mathrm{P}(\mathrm{y})$ represents probability of selecting the preferred option or choice. $(\mathrm{X})$ represents a set of explanatory variables. $(\alpha)$ and $(\beta)$ are unknown constants. $\left(U_{i}\right)$ is the stochastic error function (i) are individual fishers. 


\subsubsection{Fisher Perception Regarding and IFQ Framework Benefiting the Industry}

The first dependent variable used (IFQ) is to test fishers' preference for nontransferable dedicated access privileges. The parsimonious model for dependent variable IFQ is as follows.

Model $1 y_{i}($ IFQ $)=\alpha+\beta_{1}($ Member $)+\beta_{2}($ Fulltime $)+\beta_{3}$ (Primary_species_targeted $)+$

$$
\left.\beta_{4} \text { (Target_multiple_species }\right)+\beta_{5}(\text { Experience })+\beta_{6}(\mathrm{HP})+\mathrm{U}_{\mathrm{i}}
$$

Fishers were asked to give their belief that a non-transferable dedicated access privilege would benefit the industry. Table 8a shows which sectors of the industry are more likely to believe that IFQs (a non-transferable DAP) would benefit the industry.

Table 8a. Robust Parsimonious Logit Model of Fisher Belief that an IFQ System would benefit the Industry (Dependent variable: IFQ)

\begin{tabular}{l|l|l}
\hline Variable & Coef. & $\mathrm{p}>|\mathrm{z}|$ \\
\hline Member & -8.570 & $.042^{* *}$ \\
Fulltime & -12.011 & $.059^{*}$ \\
Primary_species_targeted & 6.015 & $.059^{*}$ \\
Target_multiple_species & -3.195 & $.030^{* *}$ \\
Crewchange & 3.182 & .107 \\
Experience & -.200 & .270 \\
HP & .001 & .690 \\
constant & -7.15 & .120 \\
\hline
\end{tabular}

$*, * *, * * *$ denotes $10 \%, 5 \%$ and $1 \%$ levels of significance respectfully; $\mathrm{P}$ values are based on robust standard errors.

Number of obs $=43$ LR $\operatorname{chi} 2(5)=\mathbf{1 6 . 9 7}$ Prob $>$ chi $2=\mathbf{0 . 0 0 4 6}$ Pseudo $R 2=\mathbf{0 . 4 1 0 7}$

Fishers that reported that they were members of an organization, club, or an association (Member), were not likely to support $(-8.570 ; \mathrm{P}=.042)$ the notion that an IFQ system would benefit the industry. Fulltime fishers disagree with the notion as well (12.011, $\mathrm{p}=.059)$. Fishers that target multiple species also disagree with the notion of an IFQ system benefitting the industry $(-3.195 ; \mathrm{p}=.030)$. A sector of the industry that agrees that an IFQ system could benefit the industry is those that target specific fisheries. The 
results show that specific fisheries support an IFQ system with a likelihood coefficient of $6.015(\mathrm{p}=.059)$. Attempts were made to determine which specific type of fisheries support this alternative management practice, but were unsuccessful. An extended version of the model was run to see how different factors, when added to the model, would change findings and extent of support or the lack thereof. Table $8 \mathrm{~b}$ is the extended version of the model.

Table 8b. Robust Extended Logit Model of Fisher Belief that an IFQ System would benefit the Industry (Dependent variable: IFQ)

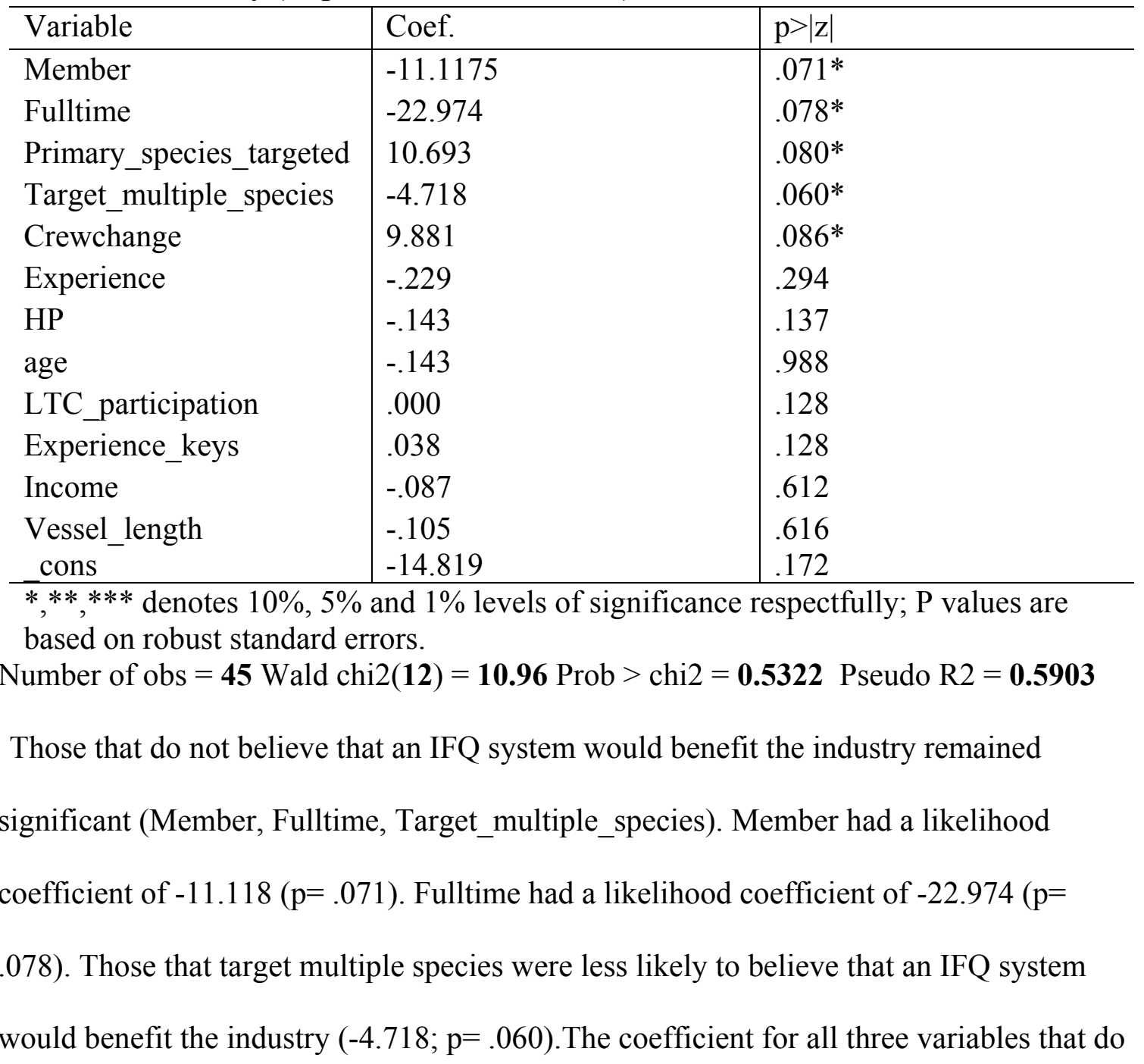


not believe that an IFQ system would benefit the industry became more negative. This indicates that as more variables were added to the model, members, fulltime fishers, and those that target multiple species, became more likely not to support the IFQ notion. The variable HP and Vessel_length were both insignificant. HP (horse power) and Vessel_length both indicate the size of the operation, implying that operation size does not contribute to any further negative support for non-transferable dedicated access privileges.

\subsubsection{Fisher Perception Regarding and ITQ Framework Benefiting the Industry}

Fishers were asked a similar question concerning transferable dedicated access privileges. Transferable DAPs are designed to give the industry more flexibility by trading or selling quotas. Table 9a shows fisher preference on if they believe transferable dedicated access privileges (ITQs) would benefit the industry.

Table 9a. Robust Parsimonious Logit Model of Fisher Belief that an ITQ System would benefit the Industry (Dependent variable: ITQ)

\begin{tabular}{l|l|l}
\hline Variable & Coef. & $\mathrm{p}>|\mathrm{z}|$ \\
\hline Member & -4.647 & $.027 * *$ \\
Fulltime & -2.345 & .145 \\
Primary_species_targeted & 1.277 & $.022^{* *}$ \\
Target_multiple_species & -1.725 & $.002^{* * *}$ \\
Crewchange & 1.069 & .415 \\
Experience & .136 & .109 \\
HP & .003 & .145 \\
cons & -6.048 & .097 \\
\hline
\end{tabular}

$*, * *, * * *$ denotes $10 \%, 5 \%$ and $1 \%$ levels of significance respectfully; P values are based on robust standard errors.

Number of obs $=\mathbf{4 7}$ Wald chi2 $(7)=\mathbf{1 3 . 7 4}$ Prob $>$ chi $2=\mathbf{0 . 0 5 6 0}$ Pseudo $\mathrm{R} 2=\mathbf{0 . 3 2 2 6}$

Those that were members indicated that they are more likely not to believe that IFQs would benefit the industry compared to non-members. The likelihood coefficient 
was -4.64 with a .027 level of significance. Those that target multiple species also are more likely not to agree that ITQs would benefit the industry $(-1.277 ; \mathrm{p}=.022)$. When running the parsimonious model, fulltime fishermen are not likely to believe that ITQs would benefit the industry, however it is not significant (when the dependent variable was IFQ, the variable Fulltime was significant). Table $9 \mathrm{~b}$ shows the extended version of the model.

Table 9b. Exteded Logit Model of Fisher Belief that an ITQ System would benefit the Industry (dependent variable: ITQ)

\begin{tabular}{l|l|l}
\hline Variable & Coef. & $\mathrm{p}>|\mathrm{z}|$ \\
\hline Member & -8.465 & $.038^{* *}$ \\
Fulltime & -3.317 & $.087^{*}$ \\
Primary_species_targeted & 2.365 & $.043^{* *}$ \\
Target_multiple_species & -2.613 & $.024^{* *}$ \\
Crewchange & -2.000 & .235 \\
Experience & .243 & $.093^{*}$ \\
HP & .007 & .225 \\
age & -.125 & $.043^{* *}$ \\
LTC_participation & 3.865 & $.043^{* *}$ \\
Experience_keys & -.036 & .457 \\
Income & .283 & .185 \\
Vessel_length & -.262 & .221 \\
cons & 7.094 & .271 \\
\hline
\end{tabular}

$*, * *, * * *$ denotes $10 \%, 5 \%$ and $1 \%$ levels of significance respectfully; $\mathrm{P}$ values are based on robust standard errors.

Number of obs $=\mathbf{4 6}$ Wald $\operatorname{chi} 2(\mathbf{1 2})=\mathbf{2 1 . 1 8}$ Prob $>$ chi $2=\mathbf{0 . 0 4 7 8}$ Pseudo $\mathrm{R} 2=\mathbf{0 . 4 7 7 9}$

In the extended version of the model, fulltime, experience, and

LTC_participation, and age all are statistically significant. Fulltime had a likelihood coefficient of $-3.317(\mathrm{p}=.087)$. Member $(-4.647 ; \mathrm{p}=.027)$ and Target_multiple_species (1.277; $\mathrm{p}=.022$ ) remained significant. Those variables that contribute not to support the notion that ITQs would benefit the industry were member, fulltime, target_ multiple_species, and age. LTC_participation, experience, and Primary_species_targeted 
all were more likely to support the ITQ framework. Those that have participated in the LTC program were $3.865(\mathrm{p}=.043)$ more likely to believe that an ITQ system would benefit the industry. As experience increased, fishers became more likely to believe that an ITQ system would benefit the industry $(.243 ; \mathrm{p}=.093)$. All coefficients of variables that were significantly less likely to be supportive increased with added variables to the model. The likelihood that members of organizations, clubs, or associations were less likely to support the notion that ITQs would benefit the industry increased by nearly double in the extended model (coefficient of the variable changed from -4.647 to -8.465 ). The variable Target_multiple_species also showed an increase in the likelihood of not believing that ITQs would benefit the industry (the coefficient is -2.163).

\subsubsection{Fisher Perception regarding IFQs Benefiting Some Operation over Others}

When speaking with fishers about DAPs, a major concern was that specific operations would benefit more than others (i.e., larger operations over smaller operations). To determine which factors can be associated with the belief that some operations would benefit more than others with the implementation of DAPs, I ran a logistical regression model. Fishers were asked if non-transferable DAPs (IFQ) and then transferable DAPs (ITQ) would benefit some operations over others. The results for the model of IFQs are listed in Table 10a. 
Table 10a. Robust Parsimonious Logit Model of Fisher Belief that an IFQ system will benefit Specific Operations over others (dependent variable: Specific_operation_ifq)

\begin{tabular}{l|l|l}
\hline Variable & Coef. & $\mathrm{p}>|\mathrm{z}|$ \\
\hline Member & -3.113 & $.025^{* *}$ \\
Fulltime & 3.420 & $.040^{* *}$ \\
Income & -.446 & $.014^{*}$ \\
HP & -.001 & .225 \\
Crew & 1.976 & $.001^{* * *}$ \\
cons & 2.401 & .085 \\
\hline
\end{tabular}

$*, * *, * * *$ denotes $10 \%, 5 \%$ and $1 \%$ levels of significance respectfully; $\mathrm{P}$ values are based on robust standard errors.

Number of obs $=\mathbf{4 3}$ Wald chi $2(\mathbf{5})=\mathbf{1 3 . 8 7}$ Prob $>$ chi $2=\mathbf{0 . 0 1 6 5}$ Pseudo $\mathrm{R} 2=\mathbf{0 . 4 1 0 7}$

Respondents that were members $(-3.113 ; p=.025)$ were not likely to answer that they believe that certain operations would benefit more than others. Higher income also leads to an increase in belief that certain operations would not benefit over others (.446; $p=.014)$. Fishers who have larger crews showed a nearly $2 \%$ increase $(p=.001)$ in the $\log$ of odds ratio that they believe that some operation would benefit more than others for every additional crew member. Fulltime fishers were likely to view that they believe specific operations would benefit over others $(3.420 ; p=.040)$.

In the extended robust version of the model (Table 10b) Member $(-3.927 ; p=.090)$, Fulltime $(3.3009 ; p=.036)$, Income $(-.602 ; p=.033)$, and Crew $(2.171 ; p=.005)$ all remain significant. The variable Crew remains significant at $1 \%$ significance. The coefficient increases slightly for the variable Member. The extended model shows that when variables are added to the model, fulltime fishers are more likely to believe that an IFQ plan would benefit certain operations over others. Also of note, there is a higher level of significance for the variable Fulltime in the extended model. The Variable HP remained insignificant in both versions of the model when the dependent variable was Specific_operation_ifq. Crew remained highly significant (under 1\%) in the extended 
model. There was a slight increase in belief that some operation would benefit more than others for Crew.

Table 10b. Extended Robust Logit Model of Fisher Belief that an IFQ system will benefit Specific Operations over others (dependent variable: Specific_operation_ifq)

\begin{tabular}{l|l|l}
\hline Variable & Coef. & $\mathrm{p}>|\mathrm{z}|$ \\
\hline Member & -3.927 & $.090^{*}$ \\
Fulltime & 3.009 & $.036^{* *}$ \\
Income & -.602 & $.033^{* *}$ \\
HP & $<-.000$ & .789 \\
Crew & 2.171 & $.005^{* * *}$ \\
Target_multiple_species & .548 & .501 \\
Experience & .050 & .236 \\
Ltc_experience & .803 & .540 \\
cons & .835 & .608 \\
\hline
\end{tabular}

$*, * *, * *$ denotes $10 \%, 5 \%$ and $1 \%$ levels of significance respectfully; $\mathrm{P}$ values are based on robust standard errors.

Number of obs $=\mathbf{4 2}$ Wald $\operatorname{chi} 2(\mathbf{8})=\mathbf{1 4 . 3 7}$ Prob $>$ chi $2=\mathbf{0 . 0 7 2 6}$ Pseudo R $2=\mathbf{0 . 4 3 7 2}$

\subsubsection{Fisher Perception regarding ITQs Benefiting Some Operation over Others}

Similar to the previous setting, a logit model was run for transferable DAPs (ITQ). Table 11a shows results of the parsimonious model. Members were once again likely not to believe that specific operations under an ITQ framework would benefit more than others $(-3.113 ; \mathrm{p}=.038)$. Crew showed a nearly $2 \%$ increase $(\mathrm{p}=.001)$ in belief that some operations would be benefitted more than others for each additional crew member. The significance level was less than one percent. The extended robust model was run adding several variables (Table $11 \mathrm{~b})$. 
Table 11a. Parsimonious Logit Model of Fisher Belief that an ITQ system will benefit Specific Operations over others (dependent variable:

Speciffic_operation_itq)

\begin{tabular}{l|l|l}
\hline Variable & Coef. & $\mathrm{p}>|\mathrm{z}|$ \\
\hline Member & -3.113 & $.038^{* *}$ \\
Fulltime & 3.420 & $.036^{* *}$ \\
Income & -.446 & $.006^{* * *}$ \\
HP & -.001 & .166 \\
Crew & 1.976 & $.001^{* * *}$ \\
cons & 2.401 & .085 \\
\hline
\end{tabular}

$*, * *, * * *$ denotes $10 \%, 5 \%$ and $1 \%$ levels of significance respectfully; $\mathrm{P}$ values are based on robust standard errors.

Number of obs $=\mathbf{4 3}$ Wald chi2 $(\mathbf{5})=\mathbf{1 8 . 4 5}$ Prob $>$ chi $2=\mathbf{0 . 0 0 2 4}$ Pseudo $\mathrm{R} 2=\mathbf{0 . 4 1 5 5}$

Table 11b. Extended Logit Model of Fisher Belief that an ITQ System will benefit Specific Operations over others (dependent variable: Speciffic_operation_itq)

\begin{tabular}{l|l|l}
\hline Variable & Coef. & $\mathrm{p}>|\mathrm{z}|$ \\
\hline Member & -5.723 & .116 \\
Fulltime & 2.158 & .166 \\
Income & -1.015 & $.052^{*}$ \\
HP & $<.000$ & .805 \\
Crew & 3.099 & $.029^{* *}$ \\
Target_multiple_species & 1.154 & .356 \\
Experience & .097 & $.039^{* *}$ \\
Ltc_experience & 2.576 & .253 \\
cons & 1.405 & .538 \\
\hline
\end{tabular}

***,*** denotes $10 \%, 5 \%$ and $1 \%$ levels of significance respectfully; $\mathrm{P}$ values are based on robust standard errors.

Number of obs $=\mathbf{4 2}$ Wald chi $2(8)=\mathbf{1 3 . 3 2}$ Prob $>$ chi $2=\mathbf{0 . 1 0 1 3}$ Pseudo $\mathrm{R} 2=\mathbf{0 . 5 0 4 2}$

When the extended model concerning ITQs and specific operations was run,

several variables lost significance. The variables Fulltime and Member both became insignificant. The variables Income $(-1.015 ; p=.052)$ and Crew $(3.099 ; p=.029)$ both retained significance although some significance was lost. The value of the coefficient increased for both variables meaning that as variables were added, Income and Crew contributed more to the belief that ITQs benefiting some operations over others also 
increased. The variable Experience was added in the extended model and was found significant (.097; $\mathrm{p}=.039)$. With increasing experience, the respondent became more likely to view that an ITQ system will benefit some operations over others. The likelihood of support was less than one percent for each additional year of experience. HP was found insignificant.

\subsubsection{Fisher Perceptions Regarding the Cost Effectiveness of a Combination of ITQs and IHQs over an MPA Framework}

The final question concerning dedicated access privileges asked fishers if a combination of ITQs and individual habitat quotas (IHQ) are more cost effective than a strictly marine protected area framework. Another logit model was run to determine the likelihood of fisher responses (Table 12a).

Table 12a. Parsimonious Robust Logit Model of Fishers' Perception that a Combination of ITQs and IHQs is more Cost Effective than Marine Protected Areas (dependent variable: itq_ihq)

\begin{tabular}{l|l|l}
\hline Variable & Coef. & $\mathrm{p}>|\mathrm{z}|$ \\
\hline Member & 2.219 & $.071^{*}$ \\
Fulltime & -3.274 & $.010^{* * *}$ \\
Primary_species_targeted & .799 & $.015^{* *}$ \\
Crewchange & 2.86 & $.029^{* *}$ \\
Age & -.131 & $.021^{* *}$ \\
cons & -1.849 & .565 \\
\hline$* * * * * *$ des
\end{tabular}

*,**,*** denotes $10 \%, 5 \%$ and $1 \%$ levels of significance respectfully; $\mathrm{P}$ values are based on robust standard errors.

Number of obs $=\mathbf{3 9}$ Wald $\operatorname{chi} 2(\mathbf{5})=\mathbf{1 1 . 6 4}$ Prob $>\operatorname{chi} 2=\mathbf{0 . 0 4 0 1}$ Pseudo $\mathrm{R} 2=\mathbf{0 . 3 2 3 2}$

In the parsimonious version of the model Member $(-2.219 ; \mathrm{p}=.071)$

Primary_species_targeted $(.799 ; \mathrm{p}=.015)$, and Crewchange $(2.86 ; \mathrm{p}=.029)$ all were more likely to respond that a combination of ITQ and IHQ systems were more cost effective than a strictly MPA framework. Fulltime fishers $(-3.274 ; \mathrm{p}=.010)$ and older fishers (- 
$.131 ; \mathrm{p}=.021)$ were more likely to respond that ITQ and IHQ systems were not more cost effective than an MPA framework. The extended model was run adding several other variables (Table 12b).

Table 12b. Extended Robust Logit Model of Fishers' Perception that a Combination of ITQs and IHQs is more Cost Effective than Marine Protected Areas (dependent variable: itq_ihq)

\begin{tabular}{l|l|l}
\hline Variable & Coef. & $\mathrm{p}>|\mathrm{z}|$ \\
\hline Member & 5.797 & $.025^{* *}$ \\
Fulltime & -6.005 & .137 \\
Primary_species_targeted & 1.646 & .170 \\
Target_multiple_species & 2.501 & .183 \\
Crewchange & 8.636 & .107 \\
Age & -.475 & $.054^{* *}$ \\
Vessel_length & -.583 & $.055^{* *}$ \\
Parents & .349 & .860 \\
household & -1.647 & .203 \\
Vessels_owned & .004 & .962 \\
cons & 14.094 & .075 \\
\hline
\end{tabular}

*,**,*** denotes $10 \%, 5 \%$ and $1 \%$ levels of significance respectfully

Number of obs $=35$ Wald chi2 $(\mathbf{1 0})=\mathbf{1 4 . 6 9}$ Prob $>$ chi $2=\mathbf{0 . 1 4 3 8}$ Pseudo R $2=\mathbf{0 . 6 2 1 3}$

The results from the extended model reveal Member remained significant and had an increased coefficient $(5.797 ; \mathrm{p}=.025)$. Fulltime, Primary_species_targeted, and Crewchange all lost significance. Age remained significant and also increased the negative likelihood that older fishers do not believe that a combination of ITQs and IHQs would be more cost effective than an MPA framework $(-.475 \mathrm{p}=.054)$.

Vessel_length was a variable that was added in the extended model and was significant ($.583: \mathrm{p}=.055)$. Fishers with increasing vessel length do believe that the combination DAPs would be more cost effective. 


\subsubsection{Fisher Perception Regarding Buffer Zones}

After the questions on dedicated access privileges, a final question on alternative management practices was asked. The final questions considered the implementation of buffer zones surrounding existing areas of no-take. A final logit model was run to determine which factors were more likely to affect the support for the creation of such zones.

The results of the parsimonious model (Table 13a) show that those who are members were more likely to support the creation of buffer zones $(1.947 ; p=.051)$. Also, fishers who had fished elsewhere in there career were more likely to support such implementations $(1.137 ; \mathrm{p}=.095)$. Fishers who responded that they were fulltime $(-1918$; $\mathrm{p}=.067)$ and those that have more experience $(-0.96 ; \mathrm{p}=.035)$ were less likely to support the creation of buffer zones.

Table 13a. Robust Parsimonious Logit Model of Fishers Support for Buffer Areas around Areas of No-take in the FKNMS (dependent variable: Buffer)

\begin{tabular}{l|l|l}
\hline Variable & Coef. & $\mathrm{p}>|\mathrm{z}|$ \\
\hline Member & 1.947 & $.051^{*}$ \\
Fulltime & -1.918 & $.067^{*}$ \\
Experience & -.096 & $.035^{* *}$ \\
Fished_elsewhere & 1.137 & $.095^{*}$ \\
Age & -.010 & .807 \\
cons & .620 & .792 \\
\hline
\end{tabular}

*,**,*** denotes $10 \%, 5 \%$ and $1 \%$ levels of significance respectfully; $\mathrm{P}$ values are based on robust standard errors.

Number of obs $=\mathbf{5 3}$ Wald chi2 $(\mathbf{5})=\mathbf{1 0 . 8 3}$ Prob $>$ chi $2=\mathbf{0 . 0 5 4 9}$ Pseudo $\mathrm{R} 2=\mathbf{0 . 3 8 4 7}$ 
Table 13b. Extended Robust Logit Model of Fishers Support for Buffer Areas around Areas of No-take in the FKNMS (dependent variable: Buffer)

\begin{tabular}{l|l|l}
\hline Variable & Coef. & $\mathrm{p}>|\mathrm{z}|$ \\
\hline Member & 1.552 & .210 \\
Fulltime & -2.258 & $.089^{*}$ \\
Experience & -.129 & $.052^{*}$ \\
Fished_elsewhere & 1.556 & $.071^{*}$ \\
Age & .006 & .880 \\
Experience-keys & .020 & .713 \\
Income & .132 & .285 \\
parents & 1.566 & .302 \\
cons & -1.635 & .477 \\
\hline
\end{tabular}

*,**,*** denotes $10 \%, 5 \%$ and $1 \%$ levels of significance respectfully; $\mathrm{P}$ values are based on robust standard errors.

Number of obs $=\mathbf{5 3}$ Wald $\operatorname{chi} 2(\mathbf{8})=\mathbf{6 . 4 3}$ Prob $>$ chi $2=\mathbf{0 . 5 9 9 0}$ Pseudo $\mathrm{R} 2=\mathbf{0 . 4 3 4 2}$

The extended model asking about buffer zones (Table 13b) have every variable from the parsimonious model except Member remain significant. The Fished_elsewhere variable $(1.556 ; \mathrm{p}=.071)$ became more significant in the extended model. Also of note, variables that remained significant all had an increase in the value of the coefficient.

\section{CHAPTER 5}

\section{DISCUSSION AND CONLUSION}

\subsection{Discussion Fisher Perception of Marine Protected Areas as Fishery Management Tools in the FKNMS}

Marine protected areas have shown to increase spawning potential for species living within the protected areas (Polacheck 1990). Furthermore, MPAs can also create a “spillover effect" into neighboring areas that are not protected (McClanahan 2001).

However, commercial fishers are often unhappy with the creation and use of MPAs as a fishery management tool (Dimech 2009, Scholz 2004). Against this backdrop, fishers in the Florida Keys were asked about the benefit of the Florida Keys National Marine 
Sanctuary. Response from those surveyed was overwhelmingly negative as over half (63\%) either strongly disagreed or disagreed with the statement that the FKNMS is a viable tool for maintaining fisheries. This finding is consistent with previous studies in the region that show fishers do not view the FKNMS as a beneficial tool for enhancing fisheries (Shivlani 2006). Fishers also showed no support for any of the no-take areas, which are zoned into the larger marine protected area. When asked if the sanctuary preservation areas had worked as planned by NOAA, $56 \%$ responded by answering no. A slightly less percentage of fishers (53\%) responded research only areas were working as planned. Finally, 57\% of fishers surveyed responded that the ecological reserves (ER) were not working according to plan. More than two thirds of all respondents said they would not support the creation of more no take areas. Support against any further expansion of no-take areas comes as fishers are becoming more neutral and less inimical toward the Florida Keys National Marine Sanctuary.

The perception of stakeholders toward the creation of the FKNMS in an earlier study shows that commercial fishers were highly negative toward creation (Suman et al. 1999). As time persisted, fishers have become less hostile toward the sanctuary $(47.76 \%$ not supporting the FKNMS creation). When fishers were asked to give initial support to the FKNMS, more than half (53\%) were not supportive. The participation of stakeholders in the creation and implementation of any management policy is a critical process to increase the awareness of that policy among stakeholders. Furthermore, fishers are less likely to comply with future expansion of policy or implementation of new regulations once they had been consulted on past policy decisions (Pita 2010). The results from this survey reveal that about half of the commercial fishers participated in some form of 
stakeholder meetings (47.06\%). Despite the resistance to the creation of more no-take areas, the majority (54\%) of fishers report that the combined zones have had no effect on their business.

When considering individual aspects of the commercial fishing industry (overall catch, condition of species targeted, competition among fishers, etc.), fishers overall believe that the FKNMS has had little effect on these aspects within the industry. Of the seven areas of interest listed in Figure 3, the condition of the species targeted, the overall catch, size of the catch, price of the catch, and the demand for product have all been reported by fishers as being not effected by the creation of the Florida Keys National Marine Sanctuary. However, two of the aspects, competition among fishers and cost of business, were reported as being negatively affected by the FKNMS creation. Furthermore over a quarter (26\%) of those surveyed reported that the FKNMS has affected the cost of business in an extremely negative way. Fishers frequently cited that they had to use more fuel to get to areas of no protection. They also said repeatedly that they believe competition among fishers had increased since the sanctuary's creation.

Fishers believe that if the FKNMS had not been created there would be little change to the condition of their fishery. All seven areas of interest were reported as being "remained the same" if the FKNMS had not been created. Fishers report that the cost of business (34\%) and competition among fishers (27\%) would better if the FKNMS had never been created. In another hypothetical situation, fishers believe that if the FKNMS were to lose all protection and not exist, the condition of the individual aspects of the industry would remain unaffected. Fishers once again feel that the cost of business (28\%) 
and the competition among fishers (17\%) would improve if the FKNMS would cease to exist.

Commercial fishers that were interviewed were far from unanimous in their opinions toward the Florida Keys National Marine Sanctuary. Fishers differed in their opinion of what components of the FKNMS they like or dislike. For example, some fishers believe that there is a genuine increase in the size of individual fish. Several fishers cited that many of the areas that were closed were some of the most productive areas. Some reported that there was greater distance traveled to fish at a greater cost. The closing of areas for protection is bound to affect some fishers in some way. In other studies when fishers are given the chance to design reserves based upon their knowledge, several areas that were proposed for closing directly affected other fishers. It was stated that "every part of the coast is critical to someone" (Scholz 2004). Others believe that many of the closed areas are in the wrong place and do not address what they believe to be the real marine problems that exists in the Florida Keys. One of the problems that was mentioned many times was the issue of water quality. Several fishers stated that water quality has not improved since the sanctuary's implementation. They wondered why such a massive project was undertaken with very little, if any, improvement in the marine environment.

Finally, fishers stated that there needs to be an increase in the amount of educated law enforcement in the region. In fact many fishers report that several of the no-take areas were areas of heavy poaching by other stakeholders. With such a large area to enforce, poaching often goes unpunished, which commercial fishers believe in turn hurts the viability of no-take areas. One fisher in particular called me to talk about specific 
improvements law enforcement officials could make to better enforce regulations in the area. Overall, fishers believe that the area is too regulated and that fishing has become harder and more stressful as fishers have to keep up with each new regulation.

\subsection{Fisher Perception for Alternative Management Frameworks}

A major concern with the implementation of a DAP system as an alternative management framework is that the fleet will be reduced create a loss of employment for individuals within the industry (Branch 2006, Brandt 2005). Although, some argue that there is increased economic efficiency and improved safety within the fleet (Criddle 2000). Fishers overwhelmingly were not supportive of DAP frameworks in for the Florida Keys. Nearly 70\% of fishers surveyed responded that IFQs (non-transferable DAP) would not benefit the industry. Seventy-two percent of those surveyed responded that ITQs (transferable DAP) would not be beneficial to the industry.

Dedicated access privileges in their rawest form are an economic tool to reduce fishing effort (Costello 2008). Furthermore, some feel the best way to organize overcapitalization within the industry is with the use of dedicated access privileges (Gislason 2000). Fishers under DAP frameworks have been shown to consolidate to better gain market power (Brandt 2005, Costello 2008). In this study, logistical regression models were run to determine which groups of the Florida Keys fishing industry were more likely to be in favor, or opposed to various forms of DAP frameworks.

The group of fishers that were members of local, regional, or national organizations or associations were unlikely to believe that ITQs or IFQs would benefit the industry. While working on this study, I had several interactions with various fishing 
clubs and organizations. All were committed to making sure their members were informed of the many types of proposed and implemented fishing regulations. Many organizations representing fishers are opposed to the use of DAPs (often referred to as "catch shares"). The results suggest that fishers who are member were well informed and are significantly opposed to DAPs, both transferable and non-transferable types. However, when asked if IFQs and ITQs would benefit some operations over others, Members were likely to respond that some operations would not benefit over others. The coefficient of likelihood of fishers that were members not believing that specific operation would benefit over others with the implementation of IFQ was only 3 percent. For ITQs, the coefficient was $5 \%$ less likely.

Often when fishery quotas are allotted for the first time, more quotas go to fishers/firms based on past landings (Brandt 2005). When quotas are transferable, it should be expected that more efficient vessels will end up with the majority of the quotas (Copes 1986). One fear among fishers is that a majority of quotas will end up with just few fishers or firms. Larger, well-funded firms or fishers may be able to push other fishers out of business and control the industry (Anderson 2008, Shivlani 2000). While conducting interviews for this study, fishers expressed concern that if "catch shares" were implemented, they didn't know how they would be able to continue fishing. Also of note, fish house owners also expressed concern that "catch shares" would force some of their fishers out of business and financially hurting their fish house. One of the hypotheses was that larger operation would support the implementation of dedicated access pivilages.. To measure larger operations, two variables were used, horsepower (HP) of the vessel and the length of that vessel (Vessel_lenght). Both horse power and vessel length were 
insignificant in all models meaning that the size of the operation does not affect fisher preference for alternative management frameworks. There could be several reasons for this. The first is that the majority of fishers in the Florida Keys have vessels under $600 \mathrm{hp}$ and the average horsepower is $380.35 \mathrm{hp}$. The mean vessel length is 30 feet. Not only does the length and power of vessels indicate size, but the number crew and the number of vessels owned can be an indication of the size of the operation. The average number crew size is two and the average number of vessels owned is 1.47 with the max number of vessels owned being three. The percentage of owning three vessels was 6.3 percent. The results show that the Florida Keys fishing industry on an individual level is a relatively modest one in terms of size of operation with many owner-operated fishers. This owner operated industry could account for the strong opposition to dedicated access privileges.

Fulltime fishers were another area of interests as they derive their entire income from fishing. Sixty-two percent of the respondents indicated they were fulltime fishers. Fulltime fishers had the strongest opposition of any variable tested to the notion that an IFQ system would be beneficial to the industry. Fulltime fishers were 22 percent less likely to believe that an IFQ framework would benefit the industry. However, when considering ITQs, fulltime fishers, while still opposing, became less likely to believe that ITQs would benefit the industry (3.3\%). Fulltime fishers also believed that a DAP system would benefit some operation over others. The variable Fulltime was significant in explaining the belief that both IFQs and ITQs would benefit some operations over others. Furthermore, fulltime fishers would not support the establishment of buffer zones around areas of no-take. 
Opposition to the belief that both transferable and non-transferable DAPs would benefit the industry was found in high significance of fishers that targeted multiple species. Reasons for fishers that target multiple species would oppose DAPs could be in the fact of the possible complicated nature of dealing with keeping track of multiple quotas for multiple species. Fishers reported the hassle of lengthy paperwork that is required for each species. Fishers interviewed were unhappy with the amount of time needed to do paperwork. Adding a further process to an already lengthy amount of paperwork, could be more than fishers are willing to accept.

Two other variables used to determine fisher preference for alternative management practices were experience and if fishers had previous experience with the Lobster Trap Certificate program (a form of DAPs). The variable Experience was significant in the extended version of the model to test if ITQs would benefit the industry. Also, experience was significant in the extended version to test if fishers believe that ITQs would benefit certain operation over others, and if fishers supported the use of buffer areas. As experience increased, fishers became more likely to believe that an ITQ system would benefit the industry. Interestingly, more experienced fishers were also more likely to believe that the ITQ system would benefit some operations over others. It is likely that the more experienced a fisher is, the more that fisher could predict changes in the fishery from subsequent policy changes. A more experienced fisher could have seen more policy changes over time, affecting their perception. Finally, more experienced fishers do not support the notion of buffer zones around areas of no take.

Participation in the LTC program could influence fishers' perception of any future DAP framework. Earlier it was shown that a large percentage of fishers target multiple 
species. This means that it is conceivable for fishers to participate in the LTC program and to also target species not managed by a DAP framework. Fishers that have participated in the LTC program were likely to believe that an ITQ program would benefit the industry. The model to test for LTC participants perceptions of an IFQ program benefiting the industry yielded insignificant results. The results from this study contradict a previous study that shows fishers are concerned with the changing social aspects of the lobster industry (Shivlani 2000). However, it is unclear whether fishers were referring to the profitability of the industry or the social aspects of the industry.

\subsection{Conclusion}

Over time, commercial fishers in the Florida Keys are becoming less inimical toward the Florida Keys National Marine Sanctuary. However, still the majority of support has not been reached. Fishers also do not support the expansion of the FKNMS or the creation of more dedicated no- take areas. According to fishers, the creation of the FKNMS has had relatively no effect on their business operation or the condition of the species they target. Fishers also believe that very little would change if the FKNMS would cease to exist. There might be, however, a change in the perception of the FKNMS if there had been an improvement in water quality, as this was a major talking point among fishers.

The results also show a substantial opposition to the use of dedicated access privileges. Some studies suggest that the implementation of DAPs can increase the profitability of the industry (Kulmala 2007). However fishers distrust the use of dedicated access privileges, mainly because DAPs have shown to reduce fleet size and the number 
of jobs within the industry (Knapp 1996). Of the groups within the industry that oppose DAPs the most are fulltime fishers and those that are members of clubs or organizations. The hypothesis that organized fishers would be less likely to support a DAP framework was supported.

It has been shown that fishers believe that the use of DAPs would benefit some operations over others (Brandt 2005, Shivlani 2000). The hypothesis that larger operations would be more likely to support a DAP framework than smaller operations was not supported. Larger operations in the form of horsepower, vessel length, and number of vessels owned show no significant preference for any form of dedicated access privilege.

The large amount of mixed fisheries and relatively small individual operation sizes could account for the non-support of dedicated access privileges as fleet reduction could happen to a large majority of fishers. Finally, fishers believe the use of DAPs in the Florida Keys would add regulations to an already heavily regulated industry. Fishers believe that this would put further strain on some of the most profitable fisheries in the country. 


\section{REFERENCES}

Anderson, L. G. (2008). The control of market power in ITQ fisheries. Marine Resource Economics, 23(1), 11-25.

Arnason, R. (1986). Management of the Icelandic demersal fisheries, Workshop on Management Option for the North Pacific Longline Fisheries.

Ban, N., Caldwell, I., Green, T., Morgan, S., O’Donnell, K., \& Selgrath, J., (2009). Diverse Fisheries Requires Diverse Solutions. Science, 323(5912), 338-339.

Beddington, J., Agnew, D., \& Clark, C. (2007). Current problems in the management of marine fisheries. Science, 316, 1713

Boyce, J.R. (1992). Individual transferable quotas and production externalities. Natural Resource Modeling. 6(4), 385.

Branch, T. A., Hilborn, R., Haynie, A. C., Fay, G., Flynn, L., Griffiths, J., Young, M. (2006). Fleet dynamics and fishermen behavior: Lessons for fisheries managers. Canadian Journal of Fisheries \& Aquatic Sciences, 63(7), 1647-1668.

Brandt, S. (2005). The equity debate: Distributional impacts of individual transferable quotas. Ocean \& Coastal Management, 48(1), 15-30.

Chu, C. (2008). Thirty years later: The global growth of ITQs and their influence on stock status in marine fisheries. Fish and Fisheries, 10(2), 217-230.

Copes, P. (1986). A critical review of the individual quota as a device in fisheries management. Land Economics, 62(3), 278.

Costello, C., Gaines, S. D., \& Lynham, J. (2008). Can catch shares prevent fisheries collapse? Science (Washington), 321(5896), 1678-1681.

Criddle, Kieth R. \& Seth Macinko. (2000). A requiem for the IFQ in the US fisheries. Marine Policy, 24(6), 461-469.

Dewees, C. M. (1989). Assessment of the implementation of individual transferable quotas in New Zealand's inshore fishery. North American Journal of Fisheries Management, 9(2), 131-139.

Dimech, M., Darmanin, M., Philip Smith, I., Kaiser, M. J., \& Schembri, P. J. (2009). Fishers' perception of a 35-year old exclusive fisheries management zone. Biological Conservation, 142(11), 2691-2702. 
Edwards, S.F. (1994). Ownership of renewable ocean resources. Marine Resource Economics, 9(3), 253-253-273.

Florida Fish and Wildlife Conservation Commission (2011). 2010 Commercial Fishery Landings Retrieved on June 9, 2011 from http://myfwc.com/research/saltwater/fishstats/commercial-fisheries/landings-inflorida/

Florida Keys Commercial Fishermen's Association (2010). Retrieved on November 4, 2010 from http://fkcfa.org/default.aspx

Florida Keys Draft Management Plan/Environmental Impact Statement. (1995). Volume I

Gibbs, M. T. (2007). Lesser-known consequences of managing marine fisheries using individual transferable quotas. Marine Policy, 31(2), 112-116.

Gislason, H., Sinclair, M., Sainsbury, K., \& O'boyle, R. (2000). Symposium overview: Incorporating ecosystem objectives within fisheries management. ICES Journal of Marine Science, 57(3), 468-475.

Glenn, H., Wattage, P., Mardle, S., Rensburg, T. V., Grehan, A., \& Foley, N. (2010). Marine protected areas - substantiating their worth. Marine Policy, 34(3), 421-430.

Halpern, B. S., Lester, S. E., \& McLeod, K. L. (2010). Placing marine protected areas onto the ecosystem-based management seascape. Proceedings of the National Academy of Sciences, 107(43), 18312-18317.

Holland, D. S., \& Schnier, K. E. (2006). Protecting marine biodiversity: A comparison of individual habitat quotas and marine protected areas. Canadian Journal of Fisheries and Aquatic Sciences, 63(7), 1481-1495.

IUCN (2009).Marine protected areas. Retrieved on November 4, 2010 from www.iucn.org

Kaplan, I. M., \& Kite-Powell, H. L. (2000). Safety at sea and fisheries management:: Fishermen's attitudes and the need for co-management. Marine Policy, 24(6), 493 497.

Klein, C.J., Chan, A., Kircher, L., Cundiff, A. J., Gardner, N., Hrovat, Y.,(2008). Striking a balance between biodiversity conservation and socioeconomic viability in the design of marine protected areas. Conservation Biology, 22(3), 691-700

Knapp, G. (1996). Thalassorama: Alaska halibut captains' attitudes towards IFQs. Marine Resource Economics, 11(1), 43-55 
Kulmala, S., Peltomaki, H., Lindroos, M., Soderkultalahti, P., \& Kuikka, S. (2007). Individual transferable quotas in the Baltic Sea herring fishery: A socio-bioeconomic analysis. Fisheries Research (Amsterdam), 84(3), 368-377.

Guenette, S., Lauck, T., \& Clark, C. (1998). Marine reserves: From Beverton and Holt to the present. Reviews in Fish Biology and Fisheries, 8(3), 251-272.

Macinko, Seth and Daniel W. Bromley. (2003-2004). Property and fisheries for the twenty-first century: Seeking coherence from legal and economic doctrine. Changing Tides in Ocean Management, 28(623), 623-661

McCay, B. J., Apostle, R., \& Creed, C. F. (1998). Individual transferable quotas, comanagement, and community: Lessons from Nova Scotia. Fisheries, 23(4), 20-24.

McClanahan, T.R. and S. Mangi. (2000). Spillover of exploitable fishes from a marine park and its effect on the adjacent fishery, Ecological Applications, 10(6), 17921805

Mid-Atlantic Fishery Advisory Council (2010). History of the Surfclam Ocean Quahog FMP. Retrieved on March 3, 2011 from http://www.mafmc.org/fmp/history/scoq.htm

Minnegal, M., \& Dwyer, P. D. (2008). Mixed messages: Buying back Australia's fishing industry. Marine Policy, 32(6), 1063-1071.

National Oceanic and Atmospheric Association (2009). Catch Shares. Retrieved on June 9, 2011 from http://www.nmfs.noaa.gov/sfa/domes_fish/catchshare/index.htm

North Pacific Fishery Management Council (2011). Halibut/Sablefish IFQ Program. Retrieved on March 3, 2011 from http://www.fakr.noaa.gov/npfmc/halibut/sablefishifq-program.html

Pikitch et al. (2004). Ecosystem-Based Fishery Management. Science, 305(5682), 346347.

Pinkerton, E., \& Edwards, D. N. (2009). The elephant in the room: The hidden costs of leasing individual transferable fishing quotas. Marine Policy, 33(4), 707-713.

Pita, C., Dickey, H., Pierce, G. J., Mente, E., \& Theodossiou, I. (2010). Willingness for mobility amongst European fishermen. Journal of Rural Studies, 26(3), 308-319.

Pomeroy, R. S., Watson, L. M., Parks, J. E., \& Cid, G. A. (2005). How is your MPA doing? A methodology for evaluating the management effectiveness of marine protected areas. Ocean \& Coastal Management,48(7-8), 485-485-502. 
Rhodes, K. L., \& Tupper, M.H. (2007). A preliminary market-based analysis of the Pohnpei, Micronesia, grouper (Serranidae: Epinephelinae) fishery reveals unsustainable fishing practices. Coral Reefs, 26(2), 335-344.

Sanchirico, J. N., \& Wilen, J. E. (2001). A bioeconomic model of marine reserve creation. Journal of Environmental Economics and Management, 42(3), 257-276.

Schaefer, M. (1959). Biological and economic aspects of the management of commercial marine fisheries. Transactions of the American Fisheries Society, 88(2), 100.

Schelle, K., \& Muse, B. (1986). Efficiency and distributional aspects of Alaska's limited entry program Retrieved fromhttp://search.proquest.com/docview/15245984?accountid=10901

Scholz, A., Bonzon, K., Fujita, R., Benjamin, N., Woodling, N., Black, P., \& Steinback, C. (2004). Participatory socioeconomic analysis: Drawing on fishermen's knowledge for marine protected area planning in California. Marine Policy, 28(4), 335-349.

Shivlani, M., et al. (2008). Knowledge, attitudes, and perceptions of management strategies and regulation of the FKNMS.US Department of Commerce.

Shivlani, Manoj P. and Milon, J Walter. (2000). Sociocultural effects of a market-based fishery management program in the Florida Keys. Coastal Management, 28(2), 133.

Smith, M. e. a. (2006). Effectiveness of marine reserves for large scale fisheries management. NRC Research Press, 63(1), 153-164.

Smith, Martin. \& Wilen, J. (2003). Economic impacts of marine reserves: The importance of spatial behavior. Journal of Environmental Economics and Modeling, 46(2), 183-206

Smith, T. e. a. (2009). Fishing for more effective incentives. Science, 323(5912), 337338.

Smith, J. N., Snyder, S. M., Berkson, J., Murphy, B. R., \& McMullin, S. L. (2009). Fisheries management of red snapper in the Gulf of Mexico: A case study. Journal of Natural Resources and Life Sciences Education, 38, 115-127.

Smith, M. D., Lynham, J., Sanchirico, J. N., \& Wilson, J. A. (2010). Political economy of marine reserves: Understanding the role of opportunity costs. PNAS, 107(43), 18300-18305. 
Smith, M. D., Zhang, J., \& Coleman, F. C. (2006). Effectiveness of marine reserves for large-scale fisheries management. Canadian Journal of Fisheries and Aquatic Sciences, 63(1), 153-164.

South Atlantic Fishery Advisory Council (2011). Limited Access Privilege (LAP) Program for the South Atlantic Snapper Grouper Fishery?. Retrived on March 3, 2011 from http://www.safmc.net/SocioEconomic/LimitedAccessPrivileges/tabid/486/Default.as px

Squires, D., Kirkley, J., \& Tisdell, C. A. (1995). Individual transferable quotas as a fisheries management tool. Reviews in Fisheries Science, 3(2), 141-169.

Standal, D., \& Aarset, B. (2008). The IVQ regime in Norway: A stable alternative to an ITQ regime? Marine Policy, 32(4), 663-668.

Stelzenmüller, V., Maynou, F., Bernard, G., Cadiou, G., Camilleri, M., Crec'hriou, R., Pérez-Ruzafa, Á. (2008). Spatial assessment of fishing effort around European marine reserves: Implications for successful fisheries management. Marine Pollution Bulletin, 56(12), 2018-2026.

Sumaila, Ussif Rashid and Claire Armstrong. (2006). Distributional and efficiency effects of marine protected areas: A study of the northeast Atlantic cod fishery. Land Economics, 82(3), 321-332

Suman, D. e. a. (1999). Perceptions and attitudes regarding marine reserves: A comparison of stakeholder groups in the Florida Keys National Marine Sanctuary. Oceans and Coastal Management, 42 (12), 1019-1040

Suuronen, P., Jounela, P., \& Tschernij, V. (2010). Fishermen responses on marine protected areas in the Baltic cod fishery. Marine Policy, 34(2), 237-243.

Thur, S. M. (2010). User fees as sustainable financing mechanisms for marine protected areas: An application to the Bonaire National Marine Park. Marine Policy, 34(1), $63-$ 69

Townsend, R. E., McColl, J., \& Young, M. D. (2006). Design principles for individual transferable quotas. Marine Policy, 30(2), 131-141.

United Nations Food and Agriculture Organization. (2009). State of World Fisheries and Aquaculture. Retrieved on February 16, 2010 from http://www.fao.org/docrep/013/i1820e/i1820e.pdf 
APPENDICES

Appendix 1- Cover Letter and Survey Instrument 


\section{WE NEED YOUR INPUT!}

How do you feel about catch shares and other management practices in the Florida Keys?

Through the Department of Earth and Environment at Florida International University, we invite you to take part in a survey that will take no more than $\mathbf{1 5}$ minutes aimed at gathering your opinion about management practices in the Florida Keys.

This survey is voluntary, but your participation is very important for this research. Please fill out the questionnaire to the best of your ability. Your responses are confidential.

Responses will only be used for statistical analysis, and will be released in summary format in which no individual respondent can be identified.

Thank you very much for your participation. If you have any questions please feel free to contact us.

Sincerely,

Brett Pierce, Researcher

Department of Earth \& Environment

Florida International University

Bpier006@fiu.edu

334.670.1190

Dr. Pallab Mozumder, Assistant Professor

Department of Earth \& Environment

Florida International University

mozumder@fiu.edu

305-348-7146 


\section{Operation Characteristics}

1 What type of gear do you use on the primary vessel? (Please choose all that apply)

\section{Trap/Cage (1)}

Hook and line (2)

Long Line (3)

Midwater Trawl (4)

Bottom Trawl (5)

Troll (6)

Spearfish (7)

Lobster diving (8)

Other, please indicate (9)

2 What is the volume (if applicable) of the on board fish boxes?

3 What is the total horse power (if applicable) of the engines on your primary vessel?

4 On a typical day, including yourself, how many crew are present?

5 In the last five years has the size of a typical crew on your primary vessel......

Increased in size (1)

Stayed the Same (2)

Decreased in size (3)

6 What is the primary specie(s) you target? (if you target multiple species, please list the top three you target)

Click to write Choice 1 (1)

Click to write Choice 2 (2)

Click to write Choice 3 (3) 
7 During the course of your career in the Florida Keys, has there been a significant change in the species in which you target?

Yes (1)

No (2)

8 If so, what species did you target, but don't target anymore?

Click to write Choice 1 (1)

Click to write Choice 2 (2)

Click to write Choice 3 (3)

\section{Opinion of Current Management Framework}

9 When it was first proposed, did you generally support establishing the Florida Keys National Marine Sanctuary (FKNMS)?

Supportive (1)

Neutral (2)

Not Supportive (3)

10 Do you support the establishment of the Florida Keys National Marine Sanctuary (FKNMS) now?

Supportive (1)

Neutral (2)

Not Supportive (3)

11 Did you participate in any stakeholder activities in formulating the FKNMS management framework? (i.e. meeting with FKNMS managers, sanctuary advisory council personnel, or other user groups such a dive boat operators)

Yes (1)

No (2) 
12 In your opinion, what do you feel was the main reason the Congress created the FKNMS? Please choose all that apply

Sustainable Fishery management (1)

Coral reef protection (2)

Reduce user impacts (3)

Reduction in User Conflicts (4)

Provide areas for scientific research (5)

Other (6)

13 When Congress created the Florida Keys National Marine Sanctuary (FKNMS), it created a series of zones designated to protect certain aspects of the ecosystem.

These include Existing Management Areas, Sanctuary Preservation Areas, Research Only Areas, and Ecological Reserves.

Sanctuary Preservation Areas (SPAs) were established to protect underwater resources ( coral, fish, and ecosystems) and no fishing, harvesting or possessing of marine life is allowed.

Do you feel as if the Sanctuary Preservation Areas designated by NOAA, are working as planned by NOAA?

Yes (1)

Neutral (2)

No (3)

14 Research Only Areas are designed for scientific research only and no one may enter without a scientific permit.

Do you feel this is a valuable part of the Florida Keys management strategy?

Yes (1)

No (2)

Neutral (6) 
15 The Ecological Reserves are designed as a haven from harvest with the goal of replenishing areas outside of their boundary and access to the ecological reserves are mostly prohibited with a few exceptions.

Do you feel the Ecological Reserves have worked in accordance with their original goal?

Yes (1)

No (2)

Neutral (3)

16 Overall, as a commercial fisherman, how do you feel these combined zones have affected your business?

My business is:

Much Worse (1)

Worse (2)

No Affect (3)

Better (4)

Much Better (5)

17 Do you feel as if the zones (in their current designation) were created more for one stakeholder group or the other, or do you feel as if Sanctuary managers were concerned with all stakeholders equally?

All stakeholders were given equal treatment (1)

Stakeholders were not given equal treatment (2)

18 Of the following user groups, please rank in order which ones have benefited the most with the creation of the FKNMS.

Dive boat operators (1)

Recreational fishermen (2)

Commercial Fishermen (3)

Scientist (4)

Environmental groups (5)

Recreational Divers/Snorkelers (6) 
19 Would you personally support creation of more no-take zones (Sanctuary Preservation Areas, Research Only, and Ecological Reserves) in the Florida Keys?

\begin{tabular}{|l|l|l|l|}
\hline & Yes (1) & Neutral (2) & No (3) \\
Sanctuary \\
$\begin{array}{l}\text { Preservation Areas } \\
\text { (SPAs) (1) }\end{array}$ & & \\
$\begin{array}{l}\text { Research Only Areas } \\
\text { (2) }\end{array}$ & & & \\
Ecological Reserves & & & \\
$(3)$ & & & \\
\hline
\end{tabular}

20 How would you respond to the following statement?

The FKNMS is an important management tool in maintaining and increasing fish habitats (from all types of fisheries).

Strongly Disagree (1)

Disagree (2)

Neither Agree nor Disagree (3)

Agree (4)

Strongly Agree (5) 
21 In your opinion, how has the creation of the Florida Keys National Marine Sanctuary (FKNMS) affected each of the following?

\begin{tabular}{|c|c|c|c|c|c|}
\hline & $\begin{array}{l}\text { Extremely } \\
\text { Negative (1) }\end{array}$ & $\begin{array}{l}\text { Negatively } \\
\text { (2) }\end{array}$ & $\begin{array}{l}\text { No Affect } \\
\text { (3) }\end{array}$ & $\begin{array}{l}\text { Positively } \\
\text { (4) }\end{array}$ & $\begin{array}{l}\text { Extremely } \\
\text { Positive (5) }\end{array}$ \\
\hline $\begin{array}{l}\text { The species } \\
\text { normally } \\
\text { targeted (1) } \\
\text { The overall } \\
\text { catch (2) } \\
\text { The } \\
\text { competition } \\
\text { among } \\
\text { fishers (3) } \\
\text { Size of catch } \\
\text { (4) } \\
\text { Cost of } \\
\text { business (5) } \\
\text { Price of } \\
\text { Catch (6) } \\
\text { Demand for } \\
\text { product (7) }\end{array}$ & & & & & \\
\hline
\end{tabular}


22 If the Florida Keys National Marine Sanctuary (FKNMS) had not been created, in your opinion, how do you feel the situation would be currently in the following areas?

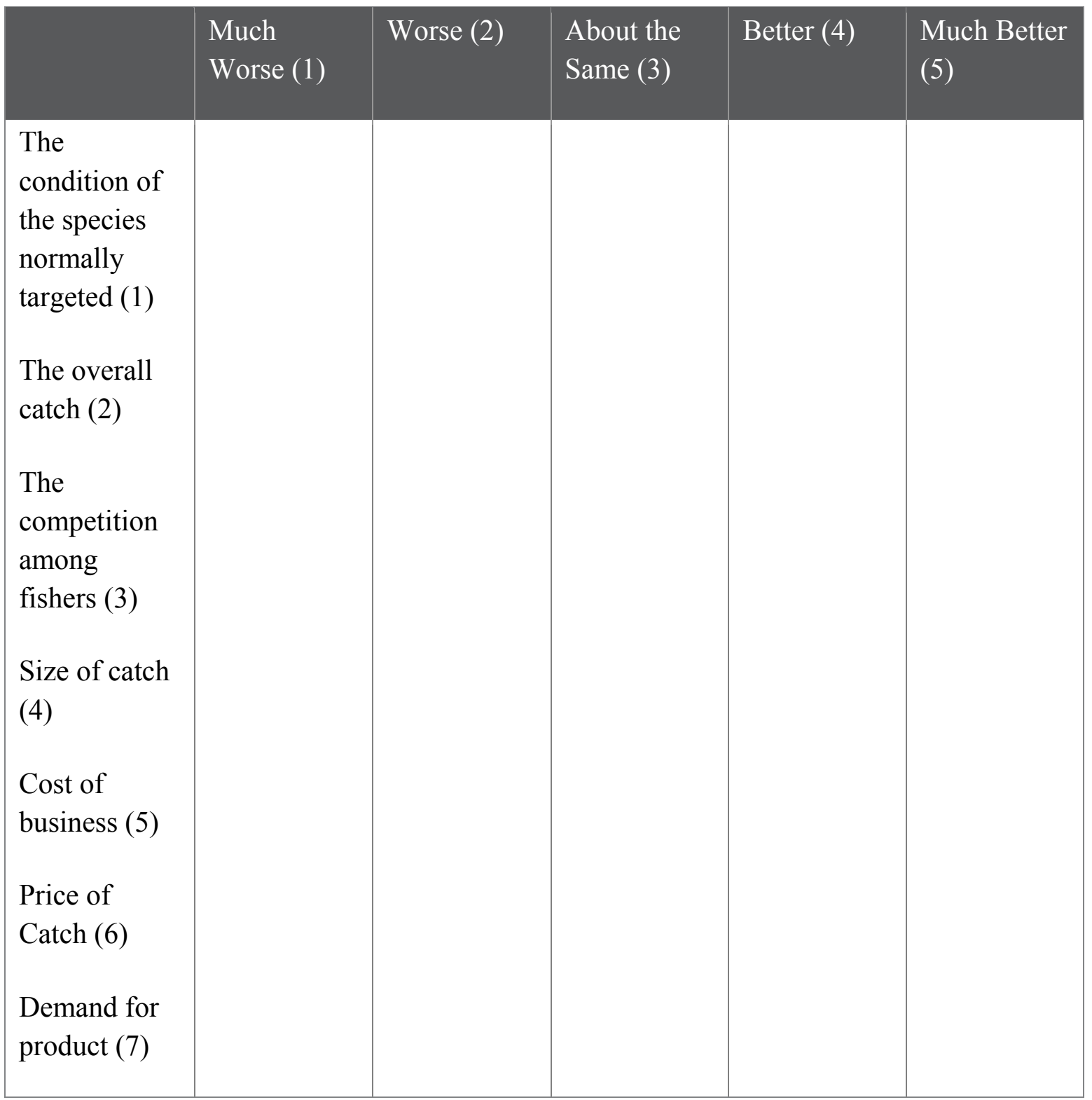


23 If all protection were to cease, and the Florida Keys National Marine Sanctuary (FKNMS) were to not exist, in your view, what situation would the following areas be in, 10 years from now?

\begin{tabular}{|c|c|c|c|c|c|}
\hline & $\begin{array}{l}\text { Much } \\
\text { Worse (1) }\end{array}$ & Worse (2) & $\begin{array}{l}\text { About the } \\
\text { Same (3) }\end{array}$ & Better (4) & $\begin{array}{l}\text { Much Better } \\
\text { (5) }\end{array}$ \\
\hline $\begin{array}{l}\text { The species } \\
\text { normally } \\
\text { targeted (1) } \\
\text { The overall } \\
\text { catch (2) } \\
\text { The } \\
\text { competition } \\
\text { among } \\
\text { fishers (3) } \\
\text { Size of catch } \\
\text { (4) } \\
\text { Cost of } \\
\text { business (5) } \\
\text { Price of } \\
\text { Catch (6) } \\
\text { Demand for } \\
\text { product (7) }\end{array}$ & & & & & \\
\hline
\end{tabular}


24 How likely is the possibility of you changing professions from a commercial fisherman?

Very Unlikely (1)

Unlikely (2)

Neutral (3)

Likely (4)

Very Likely (5)

25 Are there any other ways the Florida Keys National Marine Sanctuary has affected you or your business?

\section{Opinion of Alternative Management Framework}

26 While Marine Protected Areas (MPAs) and Total Allowable Catch (TAC) represent one type management framework, there are some alternative frameworks. An example would be Dedicated Access Privileges (DAP) or Individual Fishing Quotas (IFQs) which are a form of Catch Shares.

Dedicated Access Privileges/Catch Shares:

- Give fishers the privilege to harvest a certain portion of the total seasonal catch

- These portions can be distributed to individuals, communities, an local or regional associations.

-For more information on Dedicated Access Privileges click here

Do you feel Dedicated Access Privileges (DAP) would be a beneficial for the commercial fishing industry in the Florida Keys?

O Yes (1)

O No (2)

O Not Sure (3) 
27 Similar to Dedicated Access Privileges (DAP) and Individual Fishing Quotas (IFQ) are Individual Transferable Quotas (ITQs), commonly known as a form of catch shares.

Individual Transferable Quotas (ITQs) and transferable Catch Shares:

- give an individual/firm the privilege to harvest a portion of the total seasonal catch

- If they wish, the individual quota or a portion of the quota can be sold or leased, or an individual may buy another fisher's quota

- This is designed to reduce effort while still allowing fishers to be compensated either by selling quotas, or by fishing beyond the original quota.

- For info on the Gulf of Mexico Red Snapper ITQ (catch share) program click here

Do you feel that ITQs or transferable catch shares would be beneficial for the commercial fishing industry in the Florida Keys?

O Yes (1)

O No (2)

O Not Sure (3) 
28 In other fisheries, Dedicated Access Privilege (DAP) and Individual Transferable Quota (ITQ) systems have allowed the fishing season to be extended. If an ITQ and DAP system were to be implemented in your primary fishery do you think your primary fishery season would be extended?

\begin{tabular}{|l|l|l|l|}
\hline & Yes (1) & No (2) & Not Sure (3) \\
$\begin{array}{l}\text { Non-transferable } \\
\text { DAP or IFQ systems } \\
(1)\end{array}$ & 0 & 0 & 0 \\
$\begin{array}{l}\text { Individual } \\
\text { Transferable Quotas } \\
\text { (ITQ) or } \\
\text { Transferable Catch } \\
\text { Shares (2) }\end{array}$ & 0 & 0 & 0 \\
\hline
\end{tabular}


29 Dedicated Access Privileges (DAP) grant fishers the privilege to harvest a certain amount of the seasonal harvest. Thus fishers can potentially receive -Incentives

- Flexibility

- and reduced competition among other commercial fishers. If an incentive-based approach, like ITQs or catch shares were implemented in your particular fishery do you feel that this would be better for the industry than the current management framework?

\begin{tabular}{|l|l|l|l|} 
& \multicolumn{2}{|l|}{$\begin{array}{l}\text { Would an Dedicated Access Privilege system or a Individual } \\
\text { Transferable Quota system be better for the industry than the } \\
\text { current management framework? }\end{array}$} \\
\hline $\begin{array}{l}\text { Non-transferable } \\
\text { DAP or IFQ systems } \\
\text { (1) }\end{array}$ & 0 & No (2) & Not Sure(3) \\
$\begin{array}{l}\text { Individual } \\
\text { Transferable Quotas } \\
\text { (ITQ) or } \\
\text { Transferable Catch } \\
\text { Shares (2) }\end{array}$ & 0 & 0 & 0 \\
\hline
\end{tabular}


30 In your opinion, do you feel that a Dedicated Access Privilege (DAP) system like individual transferable quotas or catch shares would benefit particular fishers/firms in the industry more than others (i.e. small vs. large operations)?

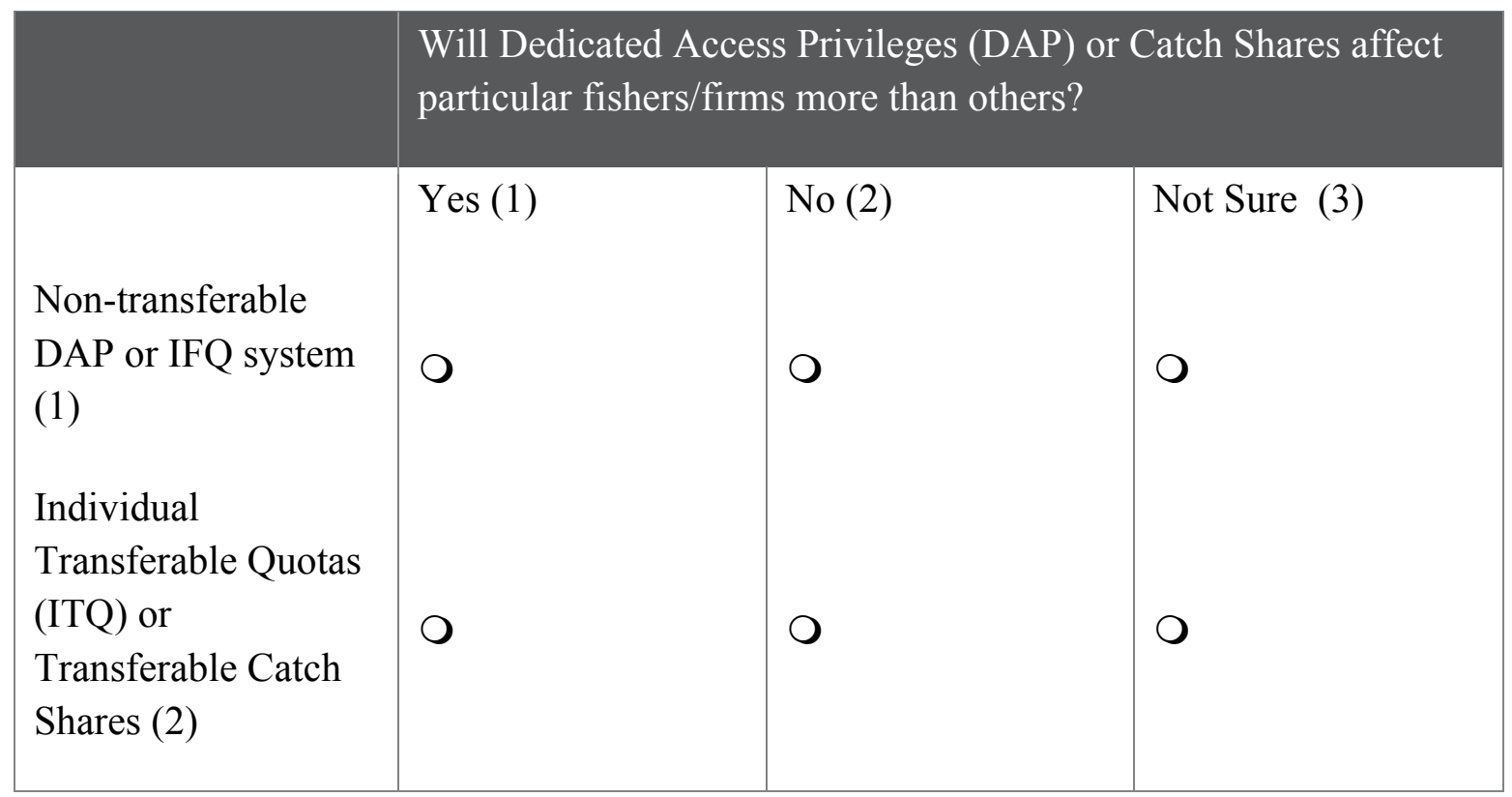

31 Do you, or have you ever participated in the Lobster Trap Certificate program?

Yes (1)

No (2)

32 When first introduced, did you support the Lobster Trap Certificate Program (LTC)?

Yes (1)

Neutral (2)

No (3)

33 Do you support the Lobster Trap Certificate (LTC) program now?

Yes (1)

Neutral (2)

No (3) 
34 Do you feel that the Lobster Trap Certificate Program has pushed smaller operators out of business?

Yes (1)

Neutral (2)

No (3)

35 Do you believe the Lobster Trap Certificate (LTC) program has been beneficial in maintaining lobster stock size in the Florida Keys?

Yes (1)

Neutral (2)

No (3)

36 If the Lobster Trap Certificate program were to be removed, what condition do you think the lobster stock be in 10 years?

Much Worse (1)

Worse (2)

About the Same (3)

Better (4)

Much Better (5)

37 Individual Transferable Quota (ITQ) systems are not without its limitations.

- Most ITQ systems focus on single species fisheries

- And ignore factors such as by-catch and habitat destruction (i.e. coral reef damage).

To mitigate these damages Individual Habitat Quotas (IHQs) could be distributed, which are similar transferable quotas, that give a fisher privileges to fish in a given area.

For example, A lobster fisher can only place a certain number of traps in a given area, but may place as many as he wish in another particular area.

Would you support such a plan?

Yes (1)

No (2)

Not Sure (3) 
38 More flexible MPA frameworks exist. A temporary marine protected area would close a certain area to fishing for a number of years, and then open that area to fishing. There would be constant, changing areas subject to openings and closings.

Do you feel this would be a positive thing for the commercial fishing industry in the Florida Keys?

Yes (1)

No (2)

Not Sure (3)

39 It has been suggested that an Individual Transferable Quotas (ITQ) combined with Individual Habitat Quotas (IHQ) management plans are relatively cost effective in terms of fishing cost and value of catch than marine protected areas or temporary area closures.

Would you agree with this statement?

Yes (1)

No (2)

Not Sure (3)

40 Buffer zones are sometimes established around no-take or no entry areas to allow for a gradual change from protected to non-protected areas. Fishermen are often allowed in these buffer areas with certain restrictions, like a limited number of lines in the water or a slot limit on targeted species.

Would the Florida Keys fish habitat be in better shape if there were buffer areas surrounding no-take, or no entry areas?

Yes (1)

No (2)

Not Sure (3) 
41 Please rank in order the management framework you would like to see in your particular fishery. (1-most preferred and 8-least preferred)

Individual transferable Quota System (1) Increase the number of no-take marine protected areas (2) Limit the number of recreational fisher permits (3) Reduce the quota for commercial fishers (4) Reduce number of commercial fishing licenses (5) A non-transferable Dedicated Access Privilege (DAP) system (6) Reduce length of fishing season (7) Restricted gear use (i.e.reducing total number of pots, lines in the water etc.) (8)

42 Which one would you prefer as the primary management framework in the Florida Keys?

Marine Protected Areas (1)

Individual Habitat Quotas (IHQ) (2)

Individual Transferable Quotas (ITQ) (3)

Temporary Marine Protected Areas (4)

Non-transferable Dedicated Access Privileges (DAP) (5)

Some combination of Quotas and MPAs (6)

Seasonal total allowable catch (TAC) (7)

43 Please describe your vessel size or the vessel you work on in feet.

44 In the last year, how many trips do you or your vessel make in a given week?

45 Since the creation of the FKNMS have your number of trips per week....

Increased Significantly (1)

Increased (2)

Stayed the same (3)

Decreased (4)

Decreased Significantly (5) 
46 Are you a full-time fisherman?

Yes (1)

No (2)

47 Were one or both of your parents a commercial fisher?

Yes (1)

No (2)

48 Do you see your children in this business?

Yes (1)

No (2)

49 Do you own the vessel you work on?

Yes (1)

No (2)

50 How many vessels do you own?

51 How many vessels do you work on?

52 How many years have you been fishing commercially?

53 How many years have you been fishing in the Florida Keys?

54 Have you ever fished elsewhere in your career?

Yes (1)

No (2) 
55 Please indicate where.

56 How do you compare fishing there compared to the Florida Keys?

Much Worse (1)

Worse (2)

About the Same (3)

Better (4)

Much Better (5)

57 What is your age?

58 What is your Ethnic background?

White (1)

Hispanic (2)

Black (3)

Asian/Pacific Islander (4)

Other (5)

59 In which of the following does you approximate annual in come fall?
Under $\$ 5,000(1)$
$\$ 5,000-\$ 9,999(2)$
$\$ 10,000-\$ 14,999$ (3)
$\$ 15,000-\$ 19,999(4)$
$\$ 20,000-\$ 24,999(5)$
$\$ 25,000-\$ 29,999(6)$
$\$ 30,000-\$ 34,999(7)$
$\$ 35,000-\$ 39,999(8)$
$\$ 40,000-\$ 44,999(9)$
$\$ 50,000-\$ 59,9999(10)$
$\$ 60,000-\$ 74,999(11)$
$\$ 75,000-\$ 99,999(12)$
Over $\$ 100,000(13)$ 
60 How many members currently reside in your household including yourself?

61 Do you belong to any local, regional, or national fishing organizations or clubs?

Yes (1)

No (2) 
Appendix 2- Mail out letter and Post Card Reminders 


\section{We Need Your Input!! \\ Para espanol, por favor siga hasta abajo}

The Department of Earth and Environment at Florida International University is conducting a study to understand the opinions of commercial fishermen about fishery management practices in the Florida Keys. With the ongoing discussion about catch shares in the region, this study will allow to express your opinions about catch shares as well as other current and alternative fishery management frameworks. Below you will find a link to a web-site with a series of questions designed to input your opinions.

The survey is voluntary, but your participation is very important to us. All responses are confidential, and your answers will be used for statistical analysis only. However, if you would like to give additional information including statements, you are more than welcome to do so by contacting us directly. The survey will take less than 30 minutes to complete and asks no identifying information at the individual level.

If you do not have access to the internet to do the survey and you would like to participate in the study, you can contact us and we can mail you a paper copy with a return envelope.

In a few months when the data is collected you will have access to a summary of the study (it will be posted at the website listed below). If you have any questions about the study, please do not hesitate to contact us directly and we will try to answer any questions you may have.

Thank you for your participation.

Esta encuesta tambien esta disponible en espanol. Para accesar en espanol por favor copie la sigiuente pagina en su internet.

Survey URL:

fiuresearch.blogspot.com

Sincerely,

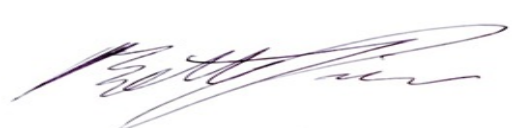

Brett Pierce, Researcher

Professor

Department of Earth \& Environment

Florida International University

Bpier006@fiu.edu

334.670.1190

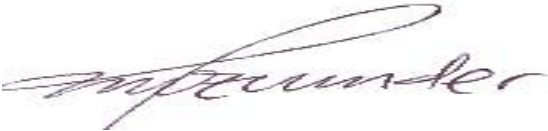

Dr. Pallab Mozumder, Assistant

Department of Earth \& Environment

Florida International University mozumder@,fiu.edu

305-348-7146 


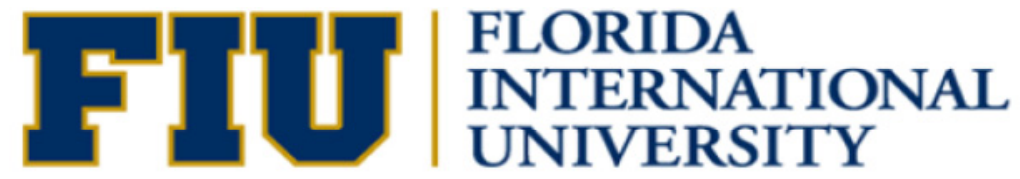

We Need Your Input!

We have contacted you previously about participating in a study regarding Catch Shares and Other Alternative Fishery Management practices in the Florida Keys.

This is just a reminder that if you have not completed the survey from the link below, please take a few

minutes to give us your opinions. The survey is voluntary, but your participation is very important to us. If you have already completed the survey, Thank You for your participation!

Esta encuesta tambien esta disponible en espanol. Para accesar en espanol por favor copie la siguente pagina en su internet.

Link to the Survey

\section{fiuresearch.blogspot.com}

If you do not have access to the internet to do the survey and you would like to participate in the study, you can contact us and we can mail you a paper copy with a return envelope.

Contact: Brett Pierce, FIU, bpier006@fiu.edu, 334.670.1190 


\section{FIU}

\section{We Need Your Input!}

We have contacted you previously about participating in a study regarding Catch Shares and Other Alternative Fishery Management practices in the Florida Keys.

This is just a reminder that if you have not completed the survey from the link below, please take a few minutes to give us your opinions. The survey is voluntary, but your participation is very important to us.

Time is running out to tell us what you think ! This is the last reminder!

If you have already completed the survey, Thank You for your participation!

Esta encuesta tambien esta disponible en espanol. Para accesar en espanol por favor copie la siguente pagina en su internet.

\section{Link to the Survey}

\section{fiuresearch.blogspot.com}

If you do not have access to the internet to do the survey and you would like to participate in the study, you can contact us and we can mail you a paper copy with a return envelope.

Contact: Brett Pierce, FIU, bpier006@fiu.edu, 334.670.1190 